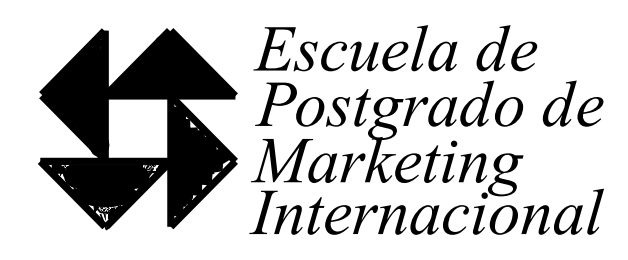

Guilherme Hoffmann

NEGOCIACIONES INTERCULTURALES EN AMÉRICA LATINA: ¿CÓMO TRATAR CON DIFERENTES COSTUMBRES E IDENTIDADES NACIONALES?

Documento presentado en el Máster en Marketing Internacional de la UNLP - Universidad Nacional de La Plata como requisito parcial para obtener el grado de Maestría en Marketing Internacional.

TUTOR DE TESIS: Dr. Carlos A. Ledesma

La Plata - Argentina

Julio / 2013 
UNIVERSIDAD NACIONAL DE LA PLATA

FACULTAD DE CIENCIAS ECONÓMICAS

ESCUELA DE POSTGRADO DE MARKETING INTERNACIONAL

El trabajo de finalización de curso "Negociaciones interculturales en América Latina: ¿Cómo tratar con diferentes costumbres e identidades nacionales?” preparado por Guilherme Hoffmann y aprobado por la Coordinación de la Escuela de Postgrado de Marketing Internacional, fue aceptado como requisito parcial para la obtención del certificado de grado de Maestría en Marketing Internacional de la UNLP - Universidad Nacional de La Plata.

La Plata - Argentina, 15 de julio de 2013.

\section{Dr. Rogelio Simonato}

Director de la Escuela de Postgrado de Marketing Internacional - UNLP

Dr. Carlos A. Ledesma

Director de Tesis 
Dedicación

"Nada de esto sería posible sin la comprensión de todos los que inspiraron la superación de más este objetivo en mi vida. En particular, mi amiga, mi esposa y compañera en todas las situaciones, Gabriela. A todas estas personas que conozco y admiro cada vez más, mi más sincero agradecimiento"

\section{Guilherme Hoffmann}


“Un país crece cuando sus diversas riquezas culturales dialogan. (...) Cuando los líderes de los distintos sectores me piden consejos, mi respuesta es siempre la misma: el diálogo, el diálogo, el diálogo."

Papa Francisco (27/07/2013)

“Money can't buy back your youth when you're old Or a friend when you're lonesome or a love that's grown cold; The wealthiest person is a pauper at times Compared to the man with a satisfied mind.

When life is over, my time has run out, My friends and my loved ones I'll leave, there's no doubt. But one thing for certain, when it comes my time, I'll leave this old world with a satisfied mind."

"El dinero no puede comprar de nuevo su juventud, cuando seas viejo O un amigo cuando estás solo, o un amor que se ha enfriado; La persona más rica es a veces un indigente En comparación con el hombre con una mente satisfecha. Cuando la vida se ha terminado, mi tiempo se ha acabado, Mis amigos y mis seres queridos me iré, no hay duda. Pero una cosa es cierta, cuando se trata de mi tiempo, Voy a dejar este viejo mundo con una mente satisfecha."

Original y traducción de la canción A Satisfied Mind de Joe "Red" Hayes \& Jack Rhodes. Canción grabada por Bob Dylan en 1980, con Saved álbum. 


\section{RESUMEN}

El objetivo de este trabajo consiste en analizar las diferentes tendencias de comportamientos culturales de los pueblos de América Latina, desde su origen precolombino, prestando asistencia en la formación del perfil actual necesario al negociador internacional que venga a negociar con los representantes de América Latina. Con base en un análisis exhaustivo de los textos acerca de la influencia cultural en el comercio mundial, buscamos demostrar cómo es posible aumentar las posibilidades de resultados positivos en una negociación intercultural con la observancia de inmutables conceptos del marketing internacional, así como el uso correcto de conceptos básicos sobre las características y estilos de negociadores latinoamericanos. Los resultados de ese trabajo muestran que los países históricamente impotentes por su función de servidumbre internacional en relación con la adopción de prácticas modernas de negociación, en sintonía con la cultura local, y aún más, que el aprovechamiento de técnicas de negociación puede estar directamente relacionado con la prevención de desperdicios de recursos y el aumento de la productividad, tanto en el ámbito público como en privado.

Palabras Claves: Negociación internacional. Negociaciones interculturales. Multicultural. Costumbres e identidades nacionales. Estilos de negociación. América Latina. 


\section{ABSTRACT}

The purpose of this thesis is to analyze the different cultural behavioral tendencies of the Latin American peoples since its pre-Columbian origins, in the hopes of aiding the shaping of today's international negotiator dealing with Latin American representatives. Based on the profound analyses of some of the most important texts about cultural influence in global negotiation, the focus is to demonstrate how it is possible to broaden chances of positive results in intercultural negotiations, provided that unchangeable concepts in international marketing are observed, as well as fundamentals on Latin American negotiator's profile and characteristics. The results of this work establish that countries historically impotent over its international servitude function will accommodate to acquire modern practices of negotiation, in tune with local culture, and moreover, that de purposeful use of negotiation techniques may be directly linked to preventing the wasting of resources and to increasing productivity, either corporative or personal.

Key Words: International negotiations. Intercultural negotiations. Multiculture. Customs and national identities. Negotiation styles. Latin America. 
1. Introducción Metodológica

1.1 Descripción de los criterios, métodos y secuencias de la elaboración del trabajo 1

1.2 Consideraciones iniciales 3

2. Panorama histórico y cultural de América Latina 8

2.1 Una cultura forjada en la sangre $\quad 8$

2.2 Un desafío cultural 11

3. Negociaciones internacionales 14

$\begin{array}{ll}3.1 \text { Tipos de negociación } & 14\end{array}$

3.2 Estilos de negociación $\quad 15$

$\begin{array}{ll}\text { 3.2.1 Estilos de Sparks } & 16\end{array}$

$\begin{array}{ll}\text { 3.2.2 Estilos de Ackoff } & 18\end{array}$

4. Influencia cultural en las negociaciones internacionales 20

4.1 La importancia de considerar la influencia cultural en las negociones internacionales

4.2 Iceberg cultural de Schneider $\quad 21$

4.3 Las dimensiones culturales de Hofstede $\quad 22$

4.3.1 Individualismo X Colectivismo 24

4.3.2 Igualitarismo X Jerarquía $\quad 24$

4.3.3 Alto X Bajo nivel de conformidad en el contexto de la comunicación 25

4.3.4 Relación entre las dimensiones 26

4.4 Las dimensiones de Schwartz $\quad 29$

5. Características de los negociadores de los principales países de América Latina 33

5.1 Una visión general 33

5.2 Argentina 34

5.3 Brasil $\quad 35$

$\begin{array}{ll}5.4 \text { Chile } & 37\end{array}$

$\begin{array}{ll}5.5 \text { Cuba } & 38\end{array}$

5.6 México 38

$\begin{array}{ll}5.7 \text { Venezuela } & 39\end{array}$

6. Factores de éxito en las negociaciones interculturales 40

6.1 Actitudes esenciales de un negociador internacional 40

6.2 Indicadores de éxito para el negociador internacional moderno 41

7. Conclusiones $\quad 44$

$\begin{array}{ll}7.1 \text { Conclusiones propiamente dichas } & 44\end{array}$

$\begin{array}{ll}7.2 \text { Próximos pasos } & 47\end{array}$

8. Bibliografía y fuentes consultadas 49 
Figura n. 01 - Primera manifestación intercultural

Figura . $^{\circ} 02$ - Segunda manifestación intercultural

Figura n. ${ }^{\circ} 03$ - Tercera manifestación intercultural: multicultura

Figura n. ${ }^{\circ} 04$ - Ubicación geográfica de los pueblos precolombinos 10

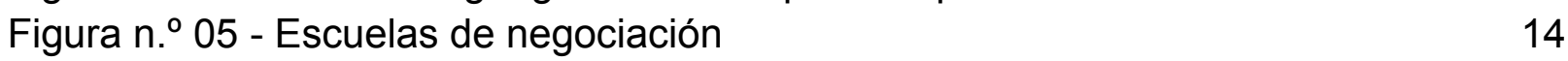

Figura n. ${ }^{\circ} 06$ - Impulsos y estilos de Sparks 17

Figura n. ${ }^{\circ} 07$ - Tipos de personalidad de Ackoff 19

Figura n. ${ }^{\circ} 08$ - Iceberg cultural de Schneider $\quad 22$

Figura n. 09 - Posicionamiento de los países en relación con los índices IDV/IDP

Figura n. ${ }^{\circ} 10$ - Dimensiones de Schwartz $\quad 30$

Figura n. ${ }^{\circ} 11$ - Modelo de Schwartz 31

Figura n. ${ }^{\circ} 12$ - Evolución de las fuerzas de Schwartz 32

Figura n. ${ }^{\circ} 13$ - Atributos del negociador argentino $\quad 35$

Figura n. ${ }^{\circ} 14$ - Características de los negociadores brasileños 36 
Tabla n. ${ }^{\circ} 01$ - Extracto de algunos índices de las dimensiones culturales 26 de Hofstede

Tabla . $^{\circ} 02$ - Mensuración de las dimensiones culturales de Hofstede 29

Tabla n. ${ }^{\circ} 03$ - Actitudes esenciales para el negociador internacional 


\section{INTRODUCCIÓN METODOLÓGICA}

\subsection{Descripción de los criterios, métodos y secuencias de la elaboración del trabajo}

La metodología utilizada para el desarrollo de este trabajo de tesis será a través de una narrativa, que se da por el análisis de conceptos y herramientas de marketing internacional, así como un estudio de los perfiles de los negociadores latinoamericanos. También se abordarán los aspectos de comportamiento y estilos de negociación practicados con el fin de hacer frente a situaciones de conflicto entre las diferentes culturas. La técnica de investigación que se utilizará es el medio empírico fáctico, donde se apoya el análisis de los hechos, a través de estudios exploratorios.

Para la investigación se utilizaron fuentes secundarias tales como libros, estadísticas, periódicos, estudios anteriores, artículos en revistas especializadas y dados de sitios del internet. Las fuentes serán consultados en tres idiomas diferentes: inglés, español y portugués.

Específicamente en el tema de las negociaciones interculturales entre los pueblos de América Latina, la producción académica es extremadamente incierta. Algunos autores tratan el tema superficialmente, es decir, como negociaciones interculturales generales. Sin embargo, para las negociaciones interculturales entre los pueblos de América Latina, los autores se reservan muy poco espacio en sus obras, a veces meros apartados que discuten el tema tan poco estudiado.

El trabajo comienza presentando un breve relato de lo que es el conflicto y cómo una situación de conflicto puede traer provechos. También describimos brevemente los tipos de conflicto. A continuación, asignaremos las definiciones de factor cultural y de negociación, dos conceptos claves para el progreso de esta tesis. En el mismo capítulo, finalizaremos parcialmente presentado como podremos definir las distintas formas de interculturalidad, en la visión de Ledesma y Domínguez (in the press) ${ }^{1}$. 
En seguida se presentará un breve relato histórico sobre la maduración del pueblo latino, que inicialmente constaba de varias tribus indígenas y distintas, pero que dentro de sus respectivos sistemas se podían ver como sociedades jerárquicas. Los recursos eran abundantes, pero las tecnologías muy primitivas. Con la excepción de las civilizaciones Mayas, Aztecas e Incas, representantes de las sociedades que más demostraron avance durante el periodo de pre-conquista española, los demás pueblos vivían geográficamente de forma distante y con la mentalidad de subsistencia.

Después de los antecedentes históricos, verificaremos como los diferentes tipos de negociación son clasificados y como esas diferentes culturas actúan para formar los diferentes estilos de negociación en el contexto global.

Armados con esta información, seremos capaces de analizar los estudios de los notables investigadores que ayudaron en la comprensión de los conceptos necesarios para comprender la formación cultural del pueblo latino americanos modernos, así como proporcionar la base técnica sobre los temas que aún serán ilustrados en la continuidad de esta tesis. En pocas palabras, observaremos los trabajos de Schneider (1997), Hofstede $(1980,2001)$, Brett $(2001,2007)$ y Schwartz $(1999)^{2}$, respectivamente.

Además, entrando en el Capítulo 5 de este documento, huiremos de una visión estereotipada proporcionada por la sociedad actual y vislumbraremos las características predominantes de los negociadores representantes de los principales países latinoamericanos.

Antes de concluir, es importante presentar una breve reseña acerca de los factores que generan el éxito en las negociaciones interculturales, especialmente las negociaciones latinoamericanas - enfoque de este trabajo - así como un relato de las actitudes esenciales del perfil del negociador internacional moderno y, por último, algunos indicadores de éxito.

En el Capítulo 7, presentaremos como conclusión, el encerramiento de esta tesis, analizando los conceptos y herramientas de marketing internacional aquí

\footnotetext{
${ }^{2}$ Respectivamente: [18], [9], [2] e [21].
} 
detallados, reforzaremos cuales técnicas y perfiles comerciales son más adecuados para que el negociador moderno trate con las diferentes costumbres e identidades culturales existentes en América Latina, siempre con el objetivo de resolver los conflictos de forma eficaz y optimizar el aprovechamiento de oportunidades.

\subsection{Consideraciones iniciales}

Empezando mi disertación citando la frase de este gran negociador argentino que también fue subsecretario de comercio exterior de Argentina, el Sr Raúl Ochoa: "Estamos frente a un mundo globalizado, de velocísimo cambio estructural en las sociedades, regiones, estados y empresas."

El mundo atraviesa una nueva era. Los avances tecnológicos, cada vez más presentes en nuestro cotidiano, se convierten en elementos de subsistencia para el hombre moderno inserido en una sociedad que sufre veloz transformación. Proveniente de eso, los problemas generados por esa sociedad actual transcienden no sólo las fronteras geográficas, sino también las fronteras culturales.

El poder de la información circula a niveles nunca antes visto, bien como la velocidad de reacción a esta comunicación en tiempo real. Juntos, son responsables por un fenómeno global en que seres humanos se mantienen constantemente incorporados en las más variadas formas de conflictos (como participante o apenas como mero espectador), sean por cuestiones de necesidades, de intereses o de opinión. ${ }^{4}$

Conflictos hacen parte de la naturaleza humana. Todos, tarde o temprano, pasan por diversas situaciones de conflicto a lo largo de la vida. Somos seres diferentes en nuestra esencia, y por lo tanto, la forma de enfrentar nuestras necesidades, nuestros intereses y nuestras opiniones, hacen con que seamos conducidos a un ambiente de conflicto.

\footnotetext{
${ }^{3}$ OCHOA, V. Raúl. Economía y comercio internacional: una visión desde el ámbito latinoamericano. In: GNAZZO et al. (2007) [7]

${ }^{4}$ MARTINELLI, VENTURA y MACHADO. (2011) [13]
} 
Erróneamente, no se debe atribuir apenas implicaciones negativas al termo conflicto, pues dependiendo de cómo la situación es administrada, los actos provenientes de un conflicto pueden llegar a ser fuentes de innovación, creatividad y hasta mismo, mayor productividad, constituyendo así un factor motivacional de la actividad generadora.

Para que exista un conflicto basta la existencia de más de una persona, con necesidades, intereses $u$ opiniones divergentes al respecto de un determinado tema. En ese caso estaríamos tratando de un conflicto denominado como interpersonal, donde el perfil comportamental de las partes involucradas posee un peso muy importante en el papel del problema y en su posible resolución. Existe también el conflicto que denominamos como intergrupal, donde el ambiente en el cual se desarrolla la desacuerdo puede crear referencias propias, pues están directamente enraizados a los aspectos culturales, así como al momento político-económico vivido por los agentes colectivos, sean ellos una organización pequeña o grande, pública o privada, o hasta mismo grupos antagónicos de individuos con diferentes convicciones. ${ }^{5}$

Para fines de comprensión de esa disertación, interpretamos el termo factor cultural como un conjunto de costumbres y hábitos de un individuo inserido en su colectividad, incluyendo aquí el linaje de su pueblo. Es decir, es un fuerte componente de como ese individuo determina su comportamiento en sociedad. Además de mucho influenciar el modo de portarse y responder ante los demás en sus actividades regulares.

Así como también necesitaremos definir el concepto de negociación. Por negociación, podemos entender que es todo proceso por el cual diferentes personas trabajan con sus diferencias. El acto de negociar significa perseguir un acuerdo mutuo por medio del diálogo. ${ }^{6}$

\footnotetext{
5 SCHMIDT y KOCHAN. (1972) Para fines de clasificación, los autores determinaron que los conflictos son definidos como: interpersonales, intergrupales e interorganizacionales. Entre tanto, para una mejor comprensión de esa disertación, serán utilizados apenas los aspectos relacionados a las denominaciones de conflictos interpersonales e intergrupales. [20]

${ }^{6}$ LUECKE. (2003) [12]
} 
Cuando dos o más miembros negocian, traen consigo su bagaje cultural, constituida por valores, intereses, opiniones y prioridades propias. La comprensión de las normas culturales es un factor esencial para el éxito de una mejor negociación internacional integrativa, donde se maximicen los resultados en función del respeto mutuo y de la elaboración de estrategias que permitan observar las diferencias culturales con el fin de transformar las interacciones sociales más eficiente.

Dos o más culturas pueden encontrar diferentes formas de interacción intercultural. Segundo Ledesma y Domínguez ${ }^{7}$, existen tres formas de manifestación intercultural:

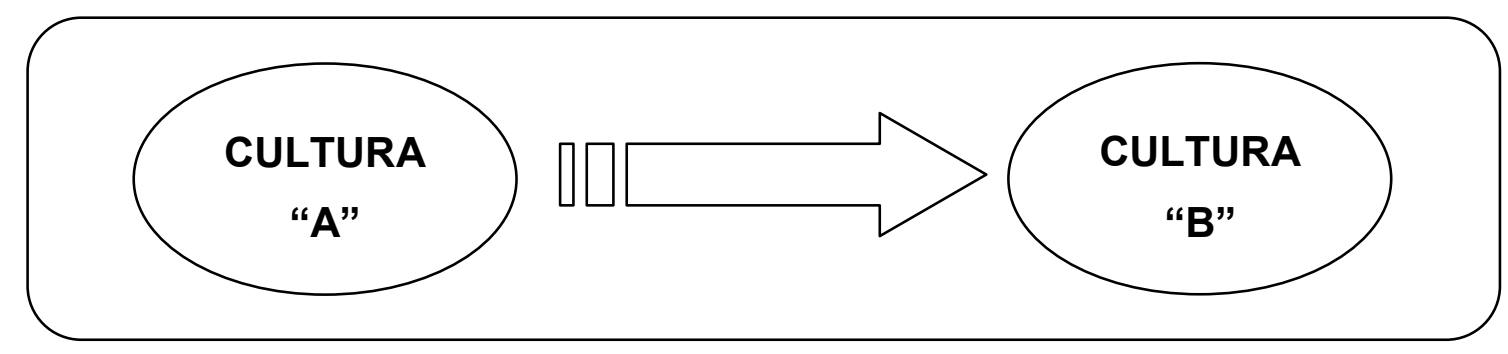

FIGURA N. 01 - PRIMERA MANIFESTACIÓN INTERCULTURAL

Fuente: Libre adaptación a partir de Ledesma y Domínguez ${ }^{8}$

La Figura $n^{\circ} 01$ demuestra la forma más simple de manifestación de la interculturalidad que es a través de etnocidio. Cuando una cultura $(A)$ aniquila la otra (B) hasta el punto de no reconocer más rasgos de la cultura dominada (B) en la expansión de la cultura dominante (A). Fue lo que sucedió después de la llegada de Cristóbal Colón en 1492. El éxodo de la emigración de los europeos del "viejo mundo" en los años siguientes condujo a un colapso en las civilizaciones indígenas hasta entonces habitantes del "nuevo mundo".

\footnotetext{
${ }^{7}$ LEDESMA y DOMÍNGUEZ. (in the press) [10]

${ }^{8}$ Idem.
} 


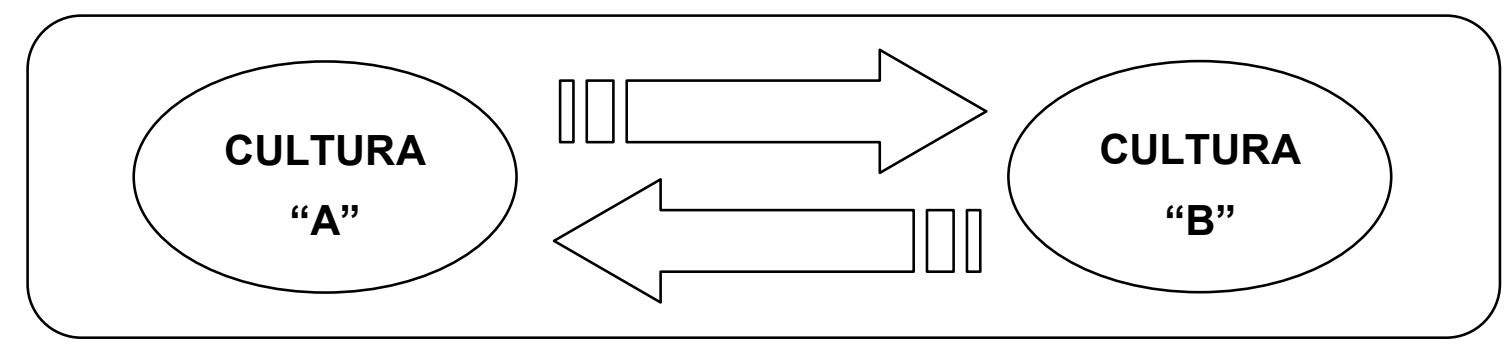

FIGURA N..$^{\circ} 02$ - SEGUNDA MANIFESTACIÓN INTERCULTURAL

Fuente: Libre adaptación a partir de Ledesma y Domínguez ${ }^{9}$

Una segunda forma de manifestación intercultural se da cuando dos o más culturas interactúan, pero no se modifican culturalmente (Figura n. ${ }^{\circ} 02$ ). Un claro ejemplo de este tipo de manifestación se dio recientemente con la alianza del Grupo Renault-Nissan ${ }^{10}$. La primera empresa del grupo tiene origen y cultura francesa y el segundo tiene origen y cultura japonesa. Juntos forman el cuarto grupo automovilístico más grande del mundo. La transición y la consolidación actual del grupo se debió a un soporte integrado de ambas culturas, con un respeto irrestricto a la individualidad de cada una de las marcas. Lo que una vez fueron dos exponentes del mercado automovilístico, hoy funcionan estratégicamente como un solo grupo, cuya vida diaria no ha cambiado a causa de las relaciones interculturales. Mientras Renault centra sus esfuerzos en el desarrollo de nuevos motores de gasolina, Nissan centra sus esfuerzos en los motores diésel. La alianza se basa en los valores de confianza y respeto mutuo, con un enfoque en el crecimiento rentable.

La Figura n. ${ }^{\circ} 03$ comprende un tercer tipo de manifestación intercultural. Este fenómeno se produce cuando dos o más culturas interactúan hasta el punto de formar una nueva variante de la cultura como resultado de la absorción de conceptos y mezcla que pertenecen a ambas partes, donde se va a compartir los únicos valores de cada cultura, pero nunca afectando en su totalidad. Esta subcultura causada por el espacio común nacido de la interacción entre dos o más culturas se llama multicultura. Observándose sólo en esta tercera y última forma de manifestación intercultural.

\footnotetext{
${ }^{9}$ LEDESMA y DOMíNGUEZ. (in the press) [10]

${ }^{10}$ [30]
} 


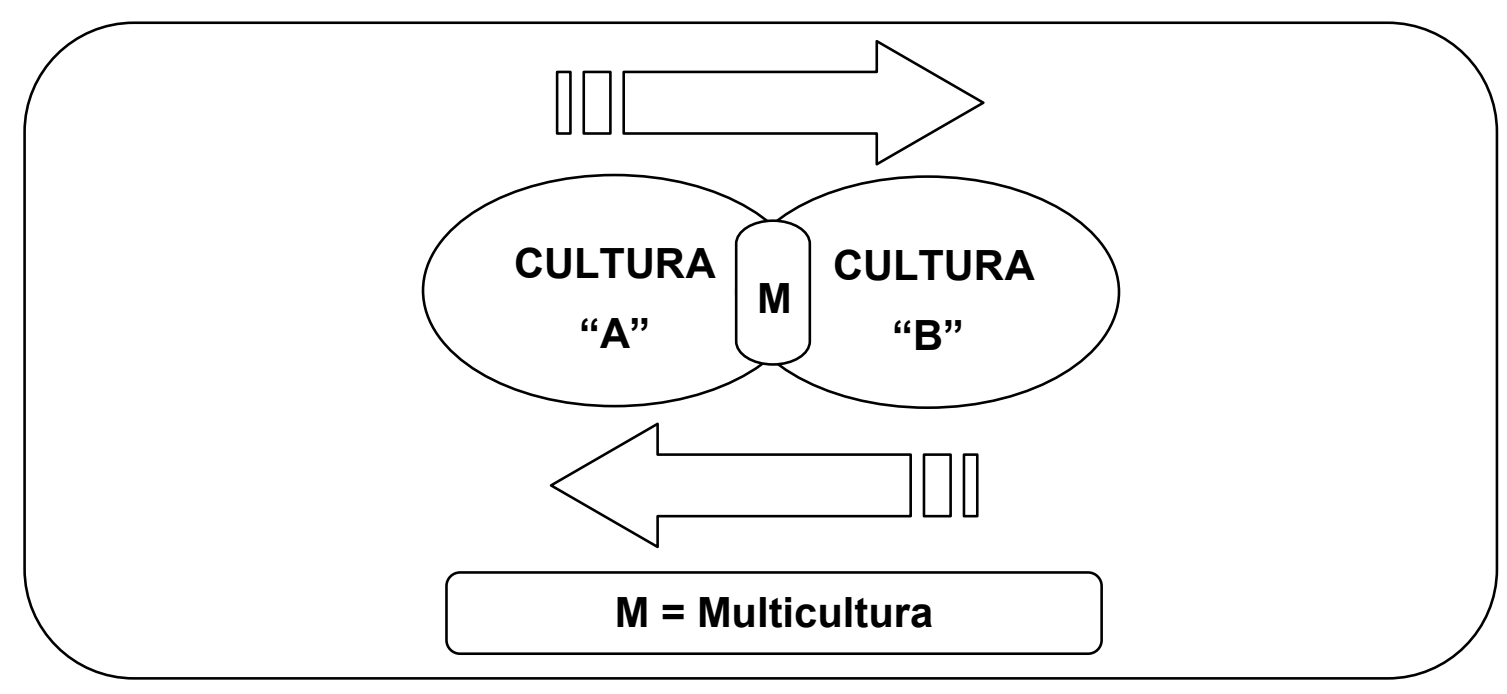

FIGURA N..$^{\circ} 03$ - TERCERA MANIFESTACIÓN INTERCULTURAL: MULTICULTURA

Fuente: Libre adaptación a partir de Ledesma y Domínguez ${ }^{11}$

Canadá es un ejemplo de territorio de manifestación multicultural. ${ }^{12}$ Los primeros exploradores franceses e ingleses que llegaron al Canadá en los siglos XVI y XVII se integraron con la sociedad aborigen predominante en el territorio canadiense a fin de construir un patrimonio único.

El multiculturalismo canadiense asume que todos son canadienses en primer lugar. Los recién llegados son bienvenidos, conocen los valores cívicos de la nueva nación y su objetivo es proporcionar a todos los individuos dentro de la sociedad un sentido de identidad que pertenece al pueblo de Canadá. Sin embargo, también se respeta el derecho de todos los ciudadanos a valorar su patrimonio cultural, creando así una comunidad comprometida con varios valores.

Cuanto más igualitaria pueda ser el cumplimiento de los derechos y deberes de la persona en situación de multiculturalismo, más seguro y legítimo ella podrá ser considerada. Una manifestación de multiculturalidad no está exenta de problemas, porque la diversidad cultural y étnica a menudo todavía se ve como una amenaza para la identidad de una nación. En algunas partes de Canadá, por ejemplo, el

\footnotetext{
${ }^{11}$ LEDESMA y DOMíNGUEZ. (in the press) [10]

${ }^{12}[27]$
} 
multiculturalismo provoca el desprecio y la indiferencia, pelea común entre los habitantes de la lengua francesa y de la lengua inglesa.

Después de la absorción de los conceptos de interculturalidad y multiculturalidad, somos capaces de darnos cuenta de que, de hecho, las metodologías aplicadas tanto en las negociaciones internacionales cuanto en la negociación domestica son extremamente muy similares, se debe prestar atención a las condiciones en la que la negociación se llevará a cabo, y en especial, como administrar la cuestión de las manifestaciones culturales. Claramente, el número de variables en un sistema de comercio internacional es mucho más grande que en comparación con las negociaciones nacionales.

Un dato alarmante es que se calcula que más del cincuenta por ciento de las negociaciones internacionales no llegan a su fin satisfactoriamente por razones de falta de conocimiento y preparación para hacer frente a los aspectos interculturales. En resumen, en las negociaciones internacionales las cuestiones culturales son muy importantes, ya que tienden a ser más pronunciadas.

\section{PANORAMA HISTÓRICO Y CULTURAL DE AMÉRICA LATINA}

\subsection{Una cultura forjada en la sangre}

En la actualidad, América Latina es representada por un pedazo de tierra que comporta poco más de $14 \%$ de la superficie terrestre ${ }^{13}$, encontramos situaciones extremamente singulares, como por ejemplo, la del Brasil, único representante de la lengua portuguesa y detentor de más de 8,5 millones de kilómetros cuadrados en su

\footnotetext{
${ }^{13}$ El término 'América Latina' fue utilizado por primera vez en 1856 por el filósofo chileno Francisco Bilbao. América Latina es compuesta por: México, por los países de América del Sur (algunos autores hacen excepción a Surinam y Guyana por considerar estos países de lenguas germánicas, no románicas - derivadas del latín), América Central continental y más tres países de América Central insular (Haití, República Dominica e Cuba).
} 
extensión territorial ${ }^{14}$; Belice, último representante a tener su independencia reconocida (setiembre de 1981) ${ }^{15}$; El Salvador, que posee apenas cerca de poco más de 21.000 kilómetros cuadrados de extensión territorial; Haití, primer país en el mundo a abolir la esclavitud (1794) y el primer latinoamericano a conseguir su independencia (1804) ${ }^{16}$; Argentina, detentora de la ciudad más austral del mundo ${ }^{17}$; en fin una gama de características político-geográficas distintas que auxiliaron a moldar hábitos y costumbres específicos para cada localidad, independiente del mismo "referencial sanguíneo" como origen.

América Latina de hoy incluye diez veces más descendientes de los pueblos indígenas que los EE.UU, por ejemplo ${ }^{18}$. Debemos reconocer que esta formación promueve una cultura indígena dominante y tradicionalista. Históricamente, la concepción de sus propias ideas sobre la división del trabajo, el vestuario, la estructura familiar y la propiedad de los bienes materiales - sólo para nombrar unos pocos - sorprendió a los colonizadores, y todavía hoy puede ser percibido por débiles huellas de un pasado no muy lejano.

Un profundo sentido de fundamentalismo se esconde debajo de las apariencias de una América Latina presente, aunque muchos países todavía se esconden vestigios de su pasado explotados por sus seres colonizadores. Mientras que los afluentes culturales indígenas molden la cultura dominante y meticulosamente diferente de los residentes del viejo mundo (y de los norteamericanos), el resultado es una cultura dominante que se vislumbra a través de un prisma negativo por parte de las élites sociales. En algunos casos, incluso enmarcado como un tipo de cultura inconveniente. Esto lleva a una amenaza para las tradiciones culturales

\footnotetext{
${ }^{14}$ Mayor extensión territorial total latinoamericana y quinta mayor extensión territorial total del mundo, superado apenas por Rusia, China, Canadá y EE.UU. [29]

${ }^{15}[26]$

${ }^{16}$ En todo el territorio americano apenas los EE.UU tuvieron su independencia declarada antes de Haití, en el año de 1776. [25]

${ }^{17}$ Ushuaia, en la provincia de la Tierra del Fuego. [28]

${ }^{18}$ BEHRENS. (2008) [1]
} 
latinoamericanas, ya que impide el pleno goce de una convivencia pacífica entre la cultura, la política, la gestión y la producción. ${ }^{19}$

Incluso antes de la llegada de los europeos al continente americano, muchas civilizaciones precolombinas ya habían desaparecido. Estos resultados sólo son posibles a través de los descubrimientos arqueológicos. En la Edad Moderna, la mayor referencia que tenemos de las civilizaciones precolombinas quedó por cuenta de las civilizaciones mesoamericanas y las civilizaciones andinas. En el primer grupo, se destacan los pueblos Olmecas, Aztecas y Mayas. En el segundo grupo, se encuentran las civilizaciones Moche, Inca y Chibcha. En particular, las civilizaciones Aztecas, Mayas e Incas, ganaron la prominencia debido a sus técnicas avanzadas de ingeniería (especialmente en sistemas de irrigación), la arquitectura, las matemáticas y la astronomía.

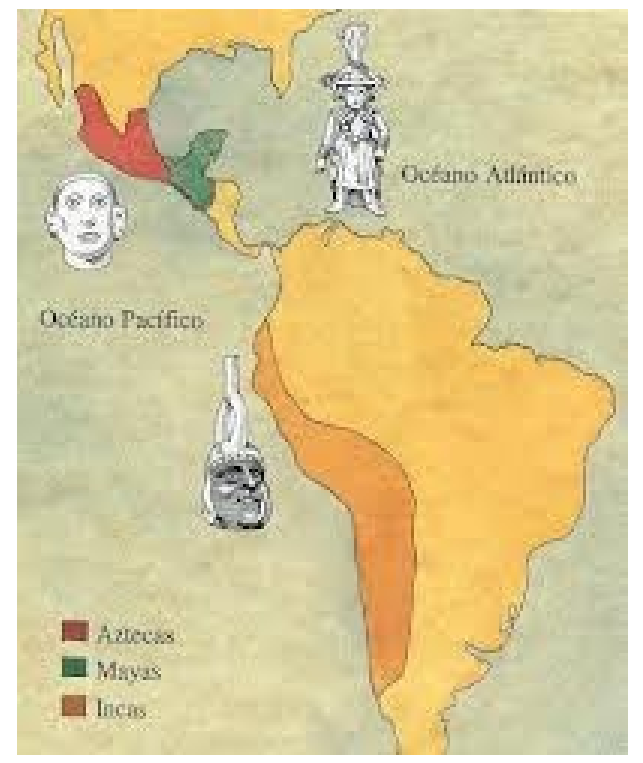

FIGURA N.ㅇ 04 - UBICACIÓN GEOGRÁFICA DE LOS PUEBLOS PRECOLOMBINOS

Fuente: Editora Abril - Revista Mundo Estranho ${ }^{20}$

Esos pueblos más evolucionados vivían en la forma de un Estado teocrático, donde los representantes del imperio eran considerados los representantes de los dioses en la Tierra. Ocurre que, España comenzó a ganar hechizos de una nación y

\footnotetext{
${ }^{19}$ BEHRENS. (2008) [1]

${ }^{20}[24]$
} 
su gobernante se convirtió en madrina de la Santa Inquisición, ${ }^{21}$ por lo tanto, los europeos atribuyeron un carácter sagrado a la conquista de tierras inhóspitas. ${ }^{22} \mathrm{En}$ 1581, D. Felipe II de España, ${ }^{23}$ cuando en una visita a Guadalajara, discursó afirmando que un tercio de los indios habitantes de América Hispánica fue diezmado, y aún, los que se encontraba vivos eran deudores de tributos a la corona española.

El sistema de comercio se llevó a cabo a través del trueque con los pueblos vecinos, pero después de la invasión y conquista de los colonizadores, fueron sometidos a una subyugación, a fin de servir como recursos (vendidos o esclavizados) para la extracción de metales preciosos antes de ser diezmados. Según Galeano (2001, p 64.): "La economía colonial latinoamericana empleó la mayor concentración de fuerza de trabajo hasta entonces conocida, para hacer posible la mayor concentración de la riqueza que jamás contó cualquier civilización en la historia mundial". ${ }^{24}$

\subsection{Un desafío cultural}

El rango variable de culturas e influencias que prevalecen en América Latina son un desafío constante para los profesionales de marketing. Las organizaciones globales necesitan un cuidado especial para actuar en mercados de países diferentes. Los seres humanos tienen más variación en el comportamiento entre las poblaciones que cualquier otra especie y por medio de un estudio aplicado se puede observar que varios casos de fracaso en las negociaciones interculturales son percibidos como una respuesta inmediata con el medio ambiente de la falta de preparación que los profesionales están expuestos.

\footnotetext{
${ }^{21}$ Reina Isabel I de Castela.

${ }^{22}$ GALEANO. (2011) [6]

${ }^{23}$ Nieto de Isabel I de Castela

${ }^{24}$ GALEANO. (2011) [6]
} 
A finales de los años 70 se hizo más clara la elaboración de un inventario de la dependencia y obediencia que América Latina fue víctima, desde que los europeos llegaron a finales del siglo XV. Preliminarmente, una dependencia del pueblo español y portugués. Luego vino el inglés, holandés, francés y últimamente, los norteamericanos. Una de las grandes certezas que se aplica desde el comienzo de este siglo es que las últimas cinco décadas, asertivamente, el escenario anterior se mantiene: la sumisión y despojo. ${ }^{25}$

La etiqueta de América Latina puede ser una descripción errónea de la Europa del siglo XIX que esconde un mayor error: los países latinoamericanos no son todos iguales. Argentina, Chile y Uruguay muestran la presencia de pequeñas trazas coloniales. Paraguay se añade al Cono Sur por buenas razones: el país es parte de una economía agrícola construida a lo largo del río Paraná. Difiere de los anteriores tres países, principalmente por la presencia masiva de su población indígena. Tal vez, el sur de Brasil puede ser parte de este grupo cultural. Allí son similares las tradiciones agrícolas y orientaciones, con una base de inmigrantes europeos que supera al resto del país. No es el bloque andino y sus culturas precolombinas: Bolivia, Perú y Ecuador. México es un poder que tiene una simbiosis cultural interesante, tiene una frontera de unos tres mil kilómetros con los EE.UU. Cuba bajo el régimen de Castro, tiene características específicas. Luego tenemos a Colombia y Venezuela que se unieron hasta 1830 y poseen características distintas de sí mismas. Brasil, con un territorio continental, separado de los demás a través de selvas, la lengua y una mezcla especial de las etnias, incluyendo la raza negra de África. ${ }^{26}$ Podemos ver claramente que las mismas ideas no siempre tienen el mismo tratamiento cuando se refiere a los diferentes países de América Latina.

Desde otro punto de vista, lo que distingue a los países de América Latina es la demarcación territorial y sus accidentes geográficos, ya que la gente habla idiomas del mismo origen, las composiciones étnicas y tienen las mismas creencias. Es decir, las similitudes más que diferentes. Básicamente, son las fronteras que limitan las relaciones entre los países.

\footnotetext{
${ }^{25}$ BEHRENS. (2008) [1]

${ }^{26}$ Idem.
} 
La globalización ha creado nuevas demandas en el mercado laboral y la imposición de toda la necesidad de buscar el desarrollo personal y profesional. Este desafío cultural y territorial es muy interesante y rico, y nos proporciona una amplia gama de opciones para que se pueda trabajar el tema.

Por lo tanto, cada vez más profesionales, especialmente aquellos que por la fuerza de la posición tienen que estar en contacto o negociar con otras culturas, tendrán que construir el conocimiento sobre estas culturas y ampliar la forma de comportamiento cuando se insertan en el mismo.

Cuando se trata de relaciones profesionales las personas tienden a ser similares en cualquier lugar. En un ambiente no contaminado, la idea de hacer una buena negociación es sin lesión de la otra parte y sin sacar provecho del objetivo principal. Es interesante notar que, mientras los negociadores, las personas muestran diferentes intereses y estilos de comunicación. Cada uno de nosotros se ve afectado por diversos factores culturales de nuestro medio ambiente y de la educación que determinan la identidad de un individuo y grupo. Sin embargo, en la mayoría de los casos no se identifica individualmente un método predecible. ${ }^{27}$

Identidad es una palabra que puede describir una cualidad distintiva o el formato de carácter propio y único. Puede dar una identidad desde fuera hacia dentro, cuando sale de otra persona o de dentro hacia fuera, cuando hay respecto al otro. En América Latina hay un sin número de identidades construidas de acuerdo con la primera hipótesis. Si las personas involucradas en una negociación intercultural llegan a compartir una identidad común, la tendencia es que no haya conflictos. ${ }^{28}$ Es decir, años de aprendizaje y sumisión sirven para calificar a un profesional internacional en una América Latina que trate con las diversas culturas. ${ }^{29}$

\footnotetext{
${ }^{27}$ FISHER, URY y PATTON. (1994) [5]

${ }^{28}$ THOMPSON. (2009) [18]

${ }^{29}$ MARTINELLI, VENTURA y MACHADO. (2011) [13]
} 


\section{NEGOCIACIONES INTERNACIONALES}

\subsection{Tipos de negociación}

Cada cultura desarrolló a lo largo de su inmensa existencia, diferentes técnicas para trabajar con problemas y sus posibles soluciones. Podemos decir que son formas particulares de negociación. Entre tanto, independiente de la influencia de una u otra cultura, podemos definir dos enfoques prioritarios para un modelo internacional de negociación: la escuela distributiva (también conocida como competitiva o tradicional) y la integradora (también conocida como colaborativa o integral). ${ }^{30 / 31}$

Por medio de la Figura n. ${ }^{\circ} 05$ podremos tener una mejor visión de la diferencia entre esas dos escuelas.

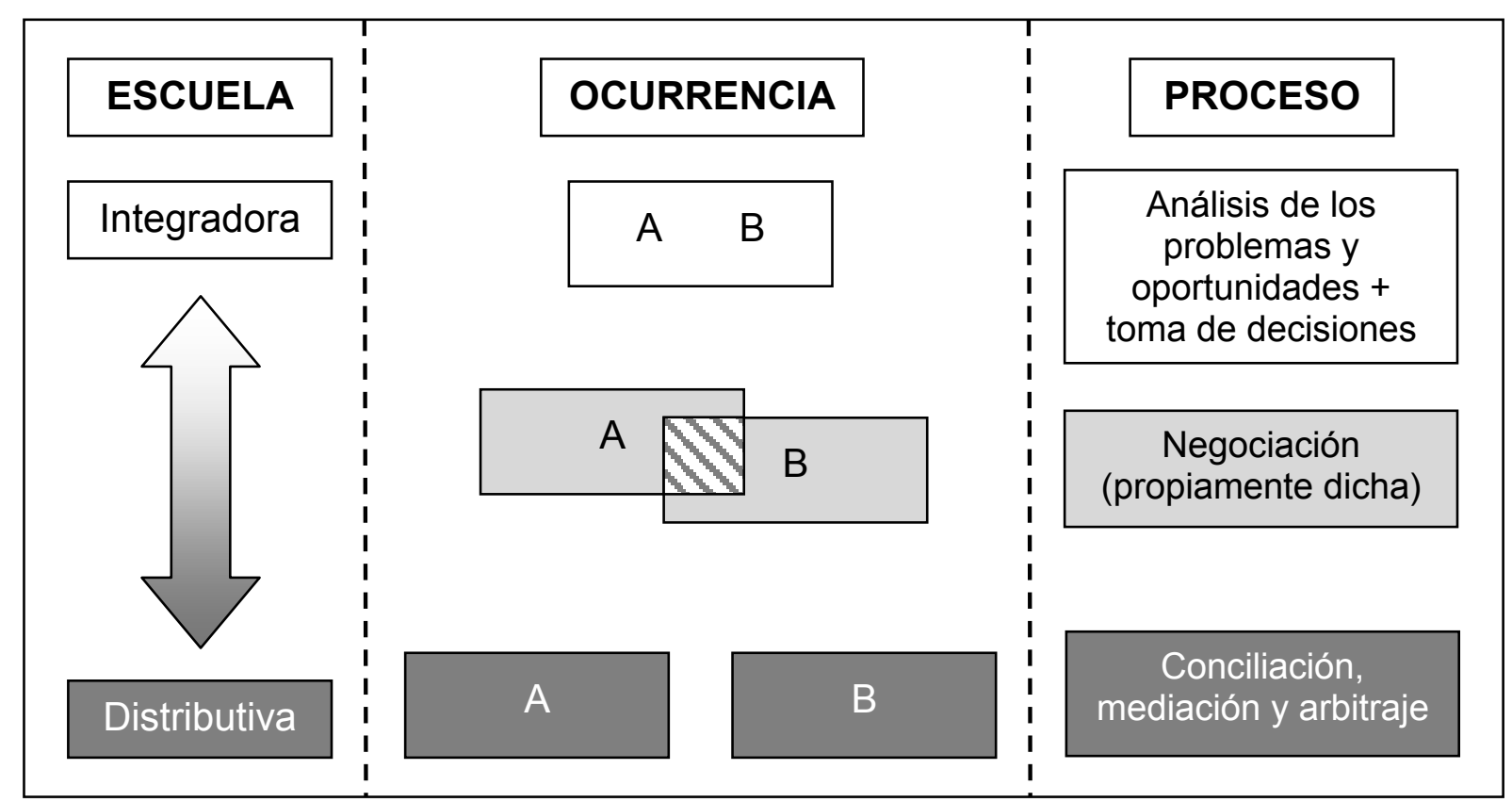

FIGURA N. ${ }^{\circ} 05$ - ESCUELAS DE NEGOCIACIÓN

Fuente: Libre adaptación a partir de Carvalhal ${ }^{32}$

\footnotetext{
${ }^{30}$ DO CARVALHAL. (2001) [4]

${ }^{31}$ PARÍS. (2010) [14]

${ }^{32}$ DO CARVALHAL. (2001) [4]
} 
Básicamente, en el abordaje utilizado por la escuela distributiva es designada por la división de lo que está siendo negociado. Una mera división, en proporciones aceptas o impuestas como justas a todas las partes involucradas del objeto de la negociación. En el abordaje de la escuela integrativa se tiene como objetivo una posibilidad de ampliación de los resultados de la negociación para todas las partes involucradas. Se parte del principio del interés común y se busca ampliar la participación de cada parte involucrada estudiando todas las posibilidades posibles de intereses y contraprestaciones.

Ambas dos escuelas se encuentran plenamente actuales. Lo que se ve en la práctica es que algunos tipos de cultura son tendenciosas a negociar en un formato repetidas veces, lo que no inhibe el hecho de utilizar un abordaje diferente caso la situación le permita o hasta mismo le convenga.

Analizando las negociaciones internacionales de una forma general, podemos verificar que hay una fuerte tendencia a la utilización de la escuela integrativa cuando verificamos la posibilidad de relaciones duraderas y que las mismas partes tengan por objetivo protagonizar sucesivas negociaciones, pero cuando vislumbramos apenas una negociación puntual, sin intenciones de asociarse, prevalece la escuela distributiva.

\subsection{Estilos de negociación}

Al evaluar los estilos de negociación de los individuos es muy importante verificar también cual es el contexto social que la cultura predominante de ese individuo está inserida. No que estas condiciones alteren los estilos de esos individuos, mas implican en cambios en la forma de actuar y en ajustes eventuales en sus características. Esos cambios pueden afectar, mismo que temporariamente, sus estilos de negociación y de decisión.

Conocer los estilos de negociación de la otra parte involucrada en una disputa vuelve más fácil la identificación de comportamientos y aspectos que podrán ser considerados buenos o malos a lo largo del proceso de envolvimiento de las partes. Eso incrementa las oportunidades de caracterizar las actitudes del negociador en la 
práctica con el objetivo de crear rapport, ${ }^{33}$ es decir, un vínculo entre las metodologías y su propio comportamiento en cuanto negociador.

Segundo Rojot, $^{34}$ individuos presentan tendencia a poseer un estilo predominante de negociación permeado por estilos complementares que son totalmente adaptables a diferentes situaciones. Esos estilos complementares, normalmente, surgen en función del tipo de negociación, de su ambiente y de las partes comprendidas. Ya el estilo predominante funciona como la espina dorsal del carácter del individuo como negociador. Siempre que algo cambia en el proceso y promueve el aislamiento de su estilo principal, el negociador se encuentra más tendencioso a ser regido por sus estilos complementares, pero en el momento en que ocurre cualquier tipo de choque, la tendencia es que el individuo abrace nuevamente su estilo predominante, pues ese es el que prevalecerá de manera decisiva sobre sus decisiones.

\subsubsection{Estilos de Sparks ${ }^{35}$}

Como podemos percibir por medio del análisis de la Figura $n .^{\circ} 06$, Sparks clasificó cuatro impulsos (área externa de la esfera mayor) que combinados entre sí proporcionan un conjunto de suposiciones sobre el ser humano, promoviendo la creación de diferentes estilos (representados por los cuadrantes de la esfera menor).

Los cuatro impulsos son:

- Control: Impulso para comandar los otros y dominar actos; creencias en la competición directa y desordenada.

- Confianza: Impulso de agregar y ser descentralizador; creencia de que el mejor trabajo es realizado en equipo.

\footnotetext{
${ }^{33}$ Rapport es un concepto de PNL - Programación Neurolingüística que significa la capacidad de entrar en el mundo de alguien. En el momento en que las partes se espejan y consiguen pensar de la misma forma, el proceso de comunicación fluye por medio de una creación de receptividad.

${ }^{34}$ ROJOT apud MARTINELLI, VENTURA y MACHADO. (2011) [13]

${ }^{35}$ SPARKS. (1992) [16]
} 
- Deferencia: Impulso de permitir que otros conduzcan la situación; creencia de que la atención activa y la tolerancia pasiva son extremamente importantes;

- Desprecio: Impulso para desdeñar de los otros; creencia de que la apatía y la impaciencia son extremamente importantes.

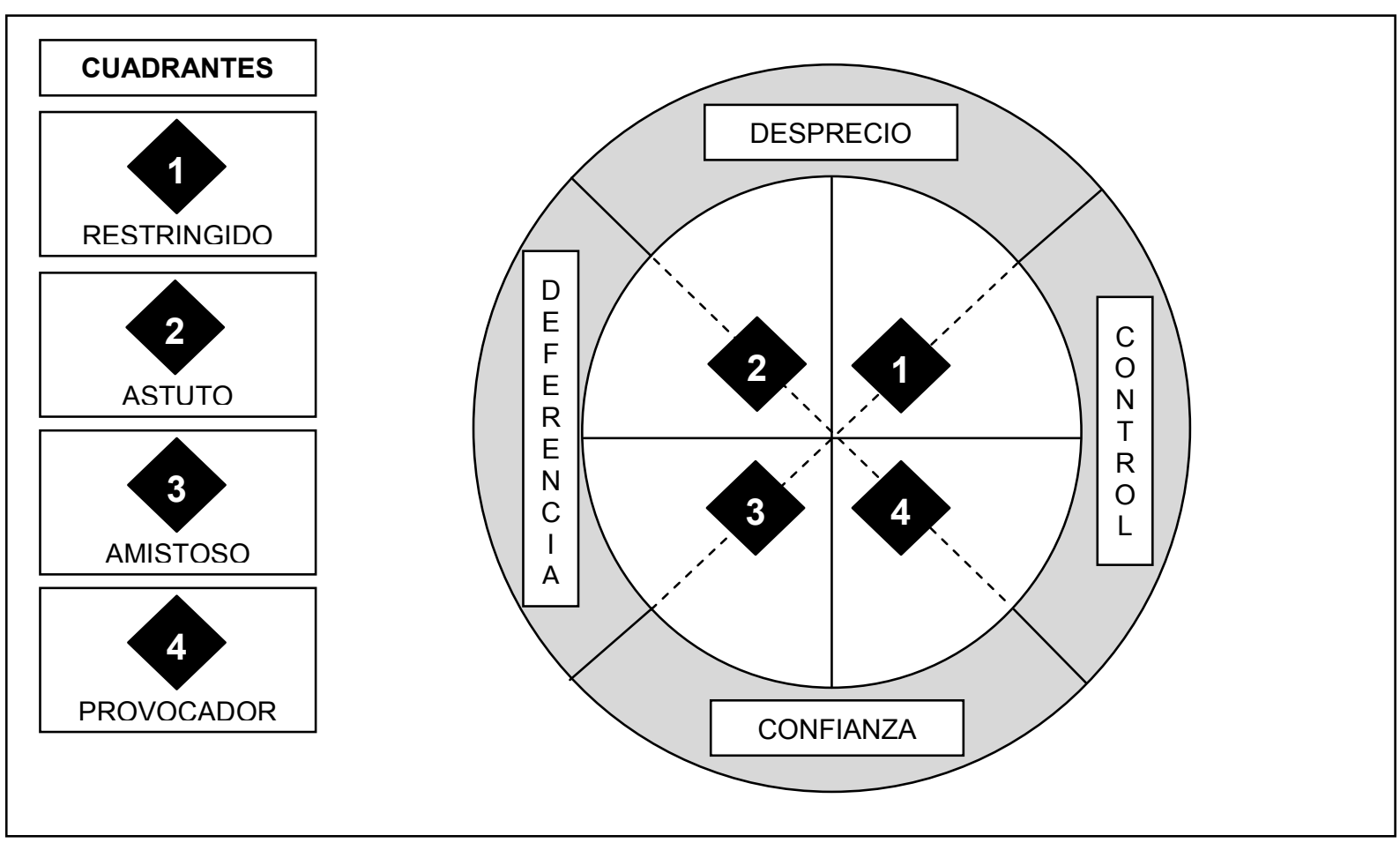

FIGURA N. 06 - IMPULSOS Y ESTILOS DE SPARKS

Fuente: Libre adaptación a partir de Sparks ${ }^{36}$

Combinaciones entre los impulsos promueve los siguientes estilos de negociación:

- Estilo Restringido: negociadores que desarrollan ese tipo de estilo no se vuelven cooperativos. En general, promueven acuerdos apenas por fuerza mayor o en último caso. Poseen un perfil competitivo e individualista exacerbados. Consideran que sus negocios cuando encerrados de la forma que fue prevista (o mejor que eso) son verdaderas victorias.

- Estilo Astuto: para ese tipo de negociador que desarrolló el estilo astuto, cualquier otro negociador debe ser evitado o mantenido a distancia. Todo al rededor

${ }^{36}$ SPARKS. (1992) [16] 
de una negociación es considerado como aversión y contrariedad. Se encuentra presente de cuerpo, mas su pensamiento está lejos. Todo lo que más importa es sobrevivir al proceso de negociación, no importa qué tipo de resultado eso traiga.

- Estilo Amistoso: negociadores que adoptan ese estilo son considerados simpáticos y colaborativos. Analizan siempre las cuestiones en un ambiente macro y consideran varias alternativas en el intuito de proporcionar clareza al negocio que está siendo ejecutado. Tiene por objetivo relacionamientos de largo plazo y son extremamente interesados en promover asociaciones estratégicas. Son los portadores del espíritu del fair play. ${ }^{37}$

- Estilo Provocador: ese tipo de estilo representa una suposición que el negociador que lo adopta procura justicia e igualdad. Contestan cuestiones constantemente en el intuito de promover resultados firmes y, en la gran mayoría de las veces, en asociación con la otra parte. Es el protagonista de la escuela integradora de negociación. Maximiza los resultados para que el mejor resultado de la negociación pueda ser alcanzado para todas las partes involucradas.

Aún segundo Sparks, los estilos comprendidos al margen directo de la Figura n. ${ }^{\circ} 06$ son iniciadores, y normalmente, poseen una probabilidad mayor de concretizar un mayor volumen de acuerdos. Los estilos comprendidos en el margen izquierdo de la misma figura se caracterizan por ser de índole reactiva, en la mayoría de las veces.

\subsubsection{Estilos de Ackoff ${ }^{38}$}

La clasificación dada por Ackoff difiere significativamente de la que vimos en el Capítulo 3.2.1, pues es utilizada para explicar la calidad de las interacciones entre los individuos en situaciones de colectividad.

\footnotetext{
${ }^{37}$ Concepto vinculado a la ética del ambiente deportivo, donde los participantes deben disputar actividades sin que el adversario sea perjudicado de propósito.

${ }^{38}$ ACKOFF. (1996) [19]
} 
Son, básicamente, dos estilos: el internalizer o introvertido y el externalizer o extrovertido. Las características de ambos son muy simples, en cuanto que el primero modifica a sí mismo para interactuar con los demás el segundo lleva a actuar en la modificación del ambiente.

Ocurre que aún hay una segunda fuerza, pues cualquier individuo encuadrado en esos dos estilos puede recibir estímulos internos (denominados como subjective) o externos (denominados como objective). Estímulos internos serían los que nacen del propio individuo en cuanto los estímulos externos son generados por el medio en el cual el propio individuo está inserido.

Tenemos entonces cuatro tipos básicos de personalidad que combinadas entre sí o no, proporcionan la definición de ocho tipos diferentes de estilos, siendo que, segundo Ackoff, cerca de $75 \%$ de los individuos poseen un tipo formado por más de una característica. Además de los cuatro tipos básicos, el autor aún creó un quinto tipo que sería el punto de equilibrio entre las características, denominado como centraversion. En total, tendremos nueve tipos, conforme demuestra la Figura $n .^{\circ} 07$.

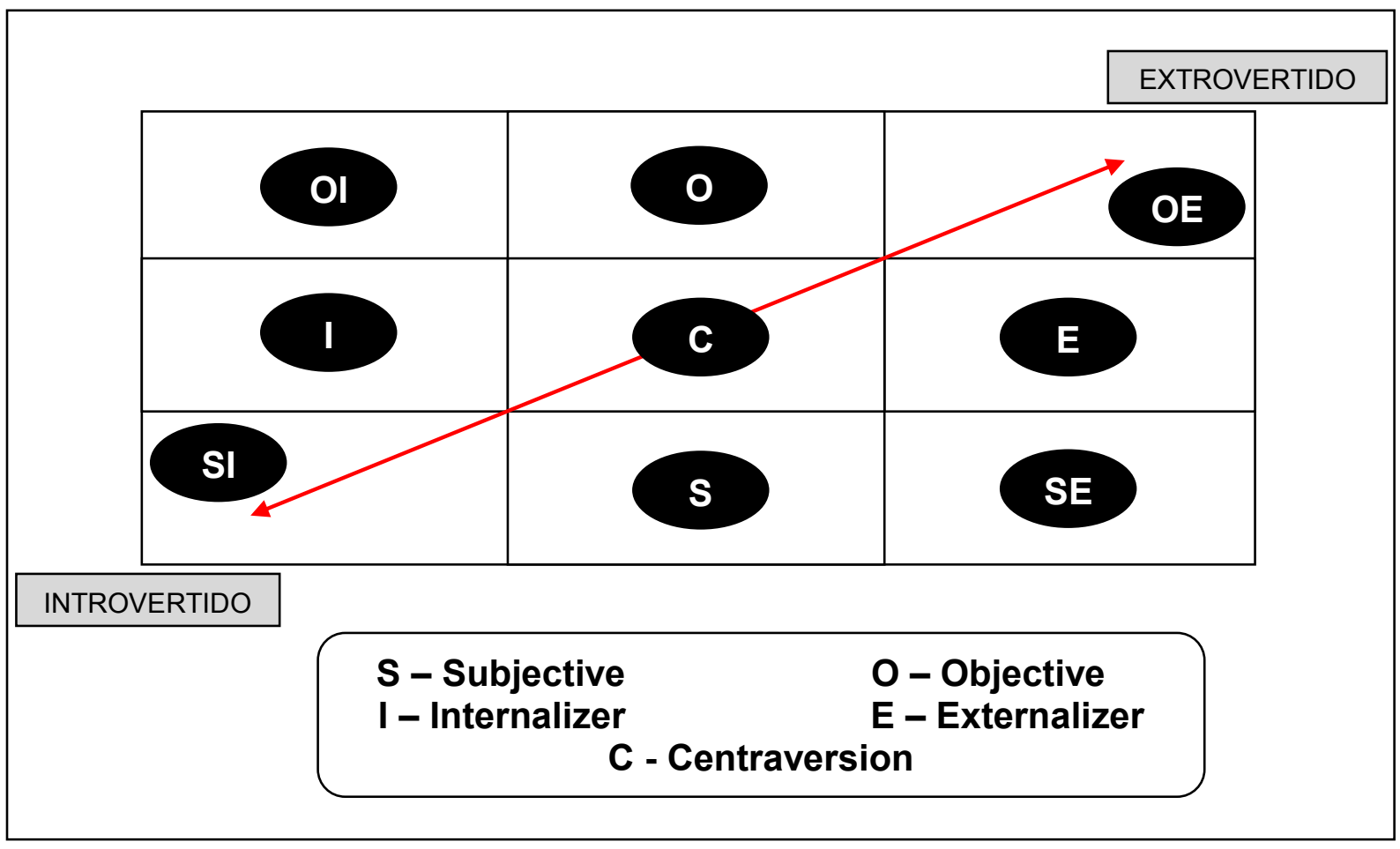

FIGURA N. ${ }^{\circ} 07$ - TIPOS DE PERSONALIDAD DE ACKOFF

Fuente: Libre adaptación a partir de Martinelli, Ventura y Machado ${ }^{39}$

${ }^{39}$ MARTINELLI, VENTURA y MACHADO. (2011) [13] 
Esa clasificación ya sirvió para analizar, examinar y aclarar los comportamientos de consumo de varios países, sobre todo en lo que se refiere a los productos masivos.

Otra interesante propuesta es poder predecir una tendencia de comportamiento de determinados pueblos, como por ejemplo lo que fue realizado en el complicado conflicto entre judíos y árabes en el Medio Oriente. Ambos grupos son clasificados como [SE], lo que significa decir que son movidos por impulsos internos, pero actúan en el medio ambiente externo, es decir, tratan de manipular a la otra parte con el fin de cumplir sus objetivos. En vista de eso, permiten muy poco espacio para la colaboración, lo que reduce las posibilidades para una posible resolución de esta antigua disputa. Los estadounidenses han intentado varias veces mediar estas fricciones, pero también son clasificados como [SE], lo que reduce las posibilidades de una solución coherente. En algunos momentos, es posible incluso condimentar la competencia. La clasificación propuesta por Ackoff se plantea para ayudar en la elección de cual cultura podría ser la más calificada para mediar en estos conflictos, como por ejemplo, los británicos o canadienses. Esos pueblos son caracterizados como [OI] - aunque durante la época del imperio, los británicos hayan sido clasificados como [SE] y cambiaron desde entonces - lo que los volverían excelentes candidatos por cuenta de ser vistos como pasivos o hasta mismo reactivos, ante situaciones de conflicto.

\section{INFLUENCIA CULTURAL EN LAS NEGOCIACIONES INTERNACIONALES}

\subsection{La importancia de considerar la influencia cultural en las negociaciones internacionales}

Las negociaciones internacionales, y en especial entre las diferentes culturas son muy comunes. Es increíble verificar que ni siempre las instituciones (públicas o privadas) están lo suficientemente preocupados con la planificación y el posible fracaso / éxito de estas negociaciones. Negociaciones interculturales ganan cada 
vez más un esbozo de elemento estratégico para una gestión eficiente de esas instituciones. ${ }^{40}$

Incluso los negociadores de una misma cultura están condenados al fracaso de sus contratos. Por lo tanto, es de suma importancia analizar aspectos que puedan identificar las principales dificultades de las negociaciones interculturales y proporcionar elementos para un proceso de negociaciones más eficaces.

El propósito principal de los próximos temas de este capítulo es proporcionar los conocimientos necesarios para facilitar la detección y comprensión de las muchas variables que influyen en la práctica de los negocios internacionales. Sólo después de estas explicaciones, podemos realizar un análisis más profundo de los problemas y las influencias culturales de América Latina y las influencias inherentes que las mismas representan en esa antigua práctica que es la negociación intercultural.

\subsection{Iceberg Cultural de Schneider ${ }^{41}$}

La figura tradicional del iceberg denota el peligro escondido detrás de una pequeña muestra de la realidad. Por lo general, alrededor de un noveno del iceberg es visible en la línea de flotación (la parte superior). El resto está sumergido.

La Figura $n^{\circ} 08$ muestra que la parte visible (por encima de la "línea de flotación") del iceberg cultural propuesto por Schneider comprende comportamientos, artefactos e instituciones, es decir, los elementos característicos de la cultura, tales como por ejemplo, sus costumbres, hábitos y tradiciones. ${ }^{42}$ Son los componentes más fuertes de la formación de una cultura, y por lo tanto los más fácilmente percibidos. Estos comportamientos de la punta del iceberg, a su vez, son una expresión de lo que viene después: valores, creencias y normas. En la base del iceberg están los supuestos fundamentales sobre el mundo y su humanidad, que sirven para impulsar los valores, creencias y normas.

\footnotetext{
${ }^{40}$ POWELL. (2012) [15]

${ }^{41}$ SCHNEIDER apud THOMPSON. (2009) [18]

${ }^{42}$ Idem.
} 


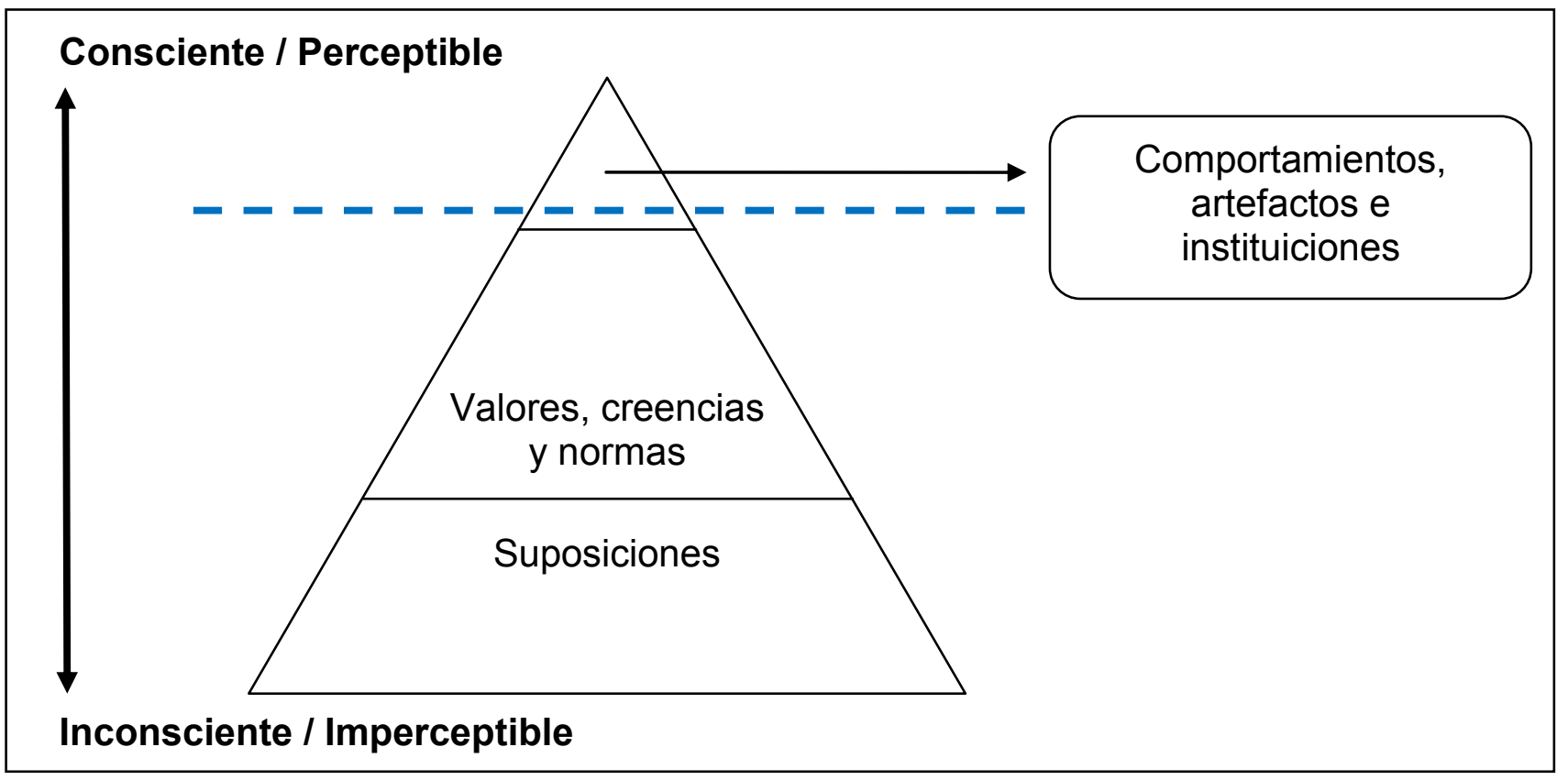

FIGURA N..$^{\circ} 08$ - ICEBERG CULTURAL DE SCHNEIDER

Fuente: Libre adaptación a partir de Thompson ${ }^{43}$

El conjunto del iceberg aquí representado, muestra una sólida y secular dependencia del topo ante los elementos de la base, pues son todas consecuencias de las manifestaciones de valores, creencias y normas fundamentales sobre el propio mundo fundamental que los sostiene. Es decir, cambiar cualquier comportamiento o costumbre del topo de ese iceberg sería lo mismo que cuestionar las creencias y valores de muchos y muchos años.

\subsection{Las dimensiones culturales de Hofstede ${ }^{44}$}

Geert Hofstede condujo una investigación en la segunda mitad del siglo pasado que fue aplicada con el auxilio de la empresa IBM en individuos de diferentes países, sexos y ocupaciones. Todos tenían en común trabajar en esa empresa o en cualquiera de sus filiales. La investigación se prolongó durante cerca de seis años y tuvo representantes de setenta y un países. En total, fueron computadas más de

\footnotetext{
${ }^{43}$ THOMPSON. (2009) [18]

${ }^{44}$ HOFSTEDE. $(1980,2001)[9]$
} 
ciento diecisiete mil observaciones. Los datos de esta investigación fueron actualizados en el principio de este siglo.

Según Hofstede, se constató que el cincuenta por ciento de las varianzas de las respuestas entre los países podría explicarse por medio de diferentes conceptos de algo que él denominó como dimensiones culturales. La concepción de tres dimensiones culturales ${ }^{45}$ tenían dos objetivos principales:

- Describir diferentes tipos de culturas con una terminología aceptable, bien definida y experimentalmente fundamentada;

- Al contrario de tener como base meras impresiones, analizar datos estructurados y fundamentados en una investigación consolidada, de forma sistemática y sobre diferentes tipos de culturas.

La investigadora Jeanne M. Brett ${ }^{46}$ publicó un estudio al respecto de cómo tener éxito en negociaciones entre individuos representantes de diferentes culturas y países. Una de las bases utilizadas por Brett fue la investigación de Hofstede, que además de definir conceptos como los de las dimensiones culturales, también clarificó estereotipos.

La clasificación de las dimensiones culturales puede ser percibida de la siguiente forma:

- Dimensión de Individualismo X Colectivismo;

- Dimensión de Igualitarismo X Jerarquía;

- Dimensión de Alto X Bajo nivel de conformidad en el contexto de la comunicación.

Estas tres dimensiones se refieren, respectivamente, a los niveles de motivación, influencia e información de un pueblo.

\footnotetext{
${ }^{45}$ Actualmente, Hofstede defiende la existencia de seis dimensiones, como por ejemplo, la que se refiere a la distribución emocional entre los sexos: masculino $X$ femenino. Ese análisis surgió después de la contribución de estudios sociológicos y antropológicos sobre su investigación inicial. Para propósito de mejor comprensión de esta tesis, estaremos analizando apenas las tres dimensiones originales.

${ }^{46}$ BRETT. (2001, 2007) [2]
} 


\subsubsection{Individualismo $X$ Colectivismo}

Estos conceptos son utilizados para distinguir dos tipos de culturas: aquellas que ponen la motivación humana básica vinculada a la preservación del individuo sobre la colectividad y aquellos que preservan la colectividad en relación con el enfoque apenas del individuo.

En el individualismo la búsqueda por la felicidad y la preocupación por el bienestar personal están por encima de cualquier otro valor. Individuos clasificados en este tipo de cultura muestran dar prioridad a sus objetivos personales, pues serán siempre más valiosos que los objetivos de un grupo en particular o de las necesidades colectivas. Las instituciones sociales y económicas están diseñadas para proteger los derechos e intereses de los individuos. En el segundo tipo de cultura, representada por el colectivismo, la motivación dominante es para con el sentimiento de pertenencia a un determinado grupo o comunidad en particular. Los individuos son parte de estos grupos y el interés del grupo prevalece sobre propio interés. Los negociadores de culturas colectivistas valoran a su familia, su empresa, su gremio, por último, su grupo social. Las instituciones sociales y económicas promueven la interdependencia de las personas, la protección de su clase social.

\subsubsection{Igualitarismo X Jerarquía}

Mientras que las sociedades con relaciones jerárquicas de poder enfatizan sus diferencias sociales hasta el punto de crear niveles jerárquicos donde representantes de una clase tomada como inferiores deben respetar a los representantes de una clase tomada como superior. Este poder puede ser ejercido de forma explícita o implícita. En el caso de una sociedad con relaciones igualitarias de poder, simplemente no hacen la distinción entre clases y por lo tanto no hay imposición de las prerrogativas entre ellos. Es decir, tienen límites de clases sociales relativamente permeables.

El igualitarismo, el poder es considerado transitorio y puede ser entendido en su forma dinámica. Todos esperan ser tratados de la misma manera. En ningún momento implica que los individuos dejen de poseer clases sociales distintas, simplemente significa que las diferencias entre las clases sociales son situacionales 
y fácilmente atravesados. En el modelo jerárquico, tenemos la situación exactamente opuesta, donde el status que tiene por base su condición social se mantiene por un largo plazo. Cuando existe la implicancia del poder social, los individuos de clases consideradas socialmente inferiores denotan deberes para con los individuos de las clases superiores y estos. En cuanto a las clases considerados seres superiores se consideran socialmente responsables por las necesidades básicas de los seres considerados inferiores. Una situación interesante se produce cuando hay un conflicto entre los seres de la misma clase. La solución más común es pasar la decisión del problema para un miembro representante de una clase social superior con el fin de mediar y arbitrar una solución que será aceptable para ambas partes.

\subsubsection{Alto X Bajo nivel de conformidad en el contexto de la comunicación}

Individuos que pertenecen a una cultura de bajo cumplimiento en el contexto de la comunicación tienden a expresarse directamente, es decir, de forma explícita. El significado está contenido en el mensaje, sin rodeos. En este caso, el acto de la comunicación se ve favorecida por la confrontación directa. Las condiciones bajo las cuales se transporta el mensaje no influyen en el proceso de negociación. Los conflictos se discuten abiertamente. Es común que las partes hagan preguntas acerca de los intereses y las posibles opciones de comercio.

En el caso de las culturas con un alto grado de cumplimiento en el contexto de la comunicación, son conocidos por expresarse indirectamente, es decir, a través de mensajes $\mathrm{o}$, a menudo contienen matices $y$ a veces incluso trampas. Son generalmente fugitivos. Los negociadores evitan confrontaciones cuando hay cualquier tipo de conflicto. El contexto del mensaje estimula conceptos preexistentes que se utilizan para obtener conocimientos necesarios. ${ }^{47}$ Las preguntas directas son cambiadas por varias propuestas seguidas, donde se contextualizan las necesidades de las partes y donde los puntos de concesión podrían existir.

\footnotetext{
${ }^{47}$ BRETT. $(2001,2007)[2]$
} 


\subsubsection{Relación entre las dimensiones}

Para interpretar mejor los resultados proporcionados por su investigación, Hofstede ${ }^{48}$ los identificó en una escala de 0 a 100 , generando índices para cada dimensión. Esto permite no sólo una medida aislada dentro de su propio grupo (dimensión), como también ayudó a crear relaciones entre las diferentes dimensiones, lo que resulta en un conocimiento más estructurado de la información obtenida.

Podemos destacar a seguir, la relación creada entre las dos primeras dimensiones descritas: Individualismo X Colectivismo e Igualitarismo $X$ Jerarquía.

La Tabla n. ${ }^{\circ} 03$ y la Figura $n .{ }^{\circ} 09$ presentan informaciones relevantes a la intersección de los resultados mencionados anteriormente, volviendo posible ver a través de un gráfico en cuadrantes no perfectos que diferencian los países por sus posiciones en relación con el Índice de Individualismo - IDV (Individualismo $X$ Colectivismo) y el Índice de Distancia de Poder - IDP (Igualitarismo X Jerarquía).

TABLA N. ${ }^{\circ} 01$

EXTRACTO DE ALGUNOS ÍNDICES DE LAS DIMENSIONES CULTURALES DE HOFSTEDE ${ }^{49}$

\begin{tabular}{|l|c|c|l|c|c|}
\hline Países & IDP & IDV & Países & IDP & IDV \\
\hline Argentina & 49 & 46 & India $\left({ }^{*}\right)$ & 77 & 48 \\
\hline Bélgica $\left.{ }^{*}\right)$ & 65 & 75 & Israel $\left({ }^{*}\right)$ & 13 & 54 \\
\hline Brasil & 69 & 38 & Jamaica $\left.{ }^{*}\right)$ & 45 & 39 \\
\hline Chile & 63 & 23 & México & 81 & 30 \\
\hline China $\left.{ }^{*}\right)$ & 80 & 20 & Panamá & 95 & 11 \\
\hline Colombia & 67 & 13 & Perú & 64 & 16 \\
\hline Costa Rica & 35 & 15 & Trinidad y Tobago $\left({ }^{*}\right)$ & 47 & 16 \\
\hline Ecuador & 78 & 08 & Sudáfrica $\left({ }^{*}\right)$ & 49 & 65 \\
\hline EE.UU $\left.{ }^{*}\right)$ & 40 & 91 & Uruguay & 61 & 36 \\
\hline El Salvador & 66 & 19 & Venezuela & 81 & 12 \\
\hline Guatemala & 95 & 06 & Promedio Mundial & $\mathbf{5 5}$ & $\mathbf{4 3}$ \\
\hline
\end{tabular}

( * ) A pesar de no ser parte de América Latina, se encuentra enumerado con objetivos de referencia.

Fuente: Libre adaptación a partir de Hofstede ${ }^{50}$

\footnotetext{
${ }^{48}$ HOFSTEDE. $(1980,2001)[9]$

${ }^{49}$ Idem.

50 Idem.
} 
El Índice de Distancia del Poder (IDP) indica la tendencia de una gran diferenciación entre los representantes de una gama superior de la estructura social en comparación con otros representantes en una escala inferior de la misma estructura.

Un análisis cuidadoso de la Figura 09 muestra como las dos dimensiones consiguen ser claramente relacionados. Los ejes IDV e IDP son fijados en relación con el promedio aritmético de todos los países participantes de la investigación, transformando esos ejes en un promedio mundial. Guatemala, Ecuador y Panamá son los países con bajo poder de individualidad y, que hace referencia a esta investigación, deberán ser tratados como países que predominan intereses colectivos. Mientras tanto, Argentina es el único representante de los países de América Latina que se encuentra más allá de la media mundial y puede ser denominado como un país de características individualistas. Lo curioso es que a pesar de ser considerado como un país individualista, todavía se observan ciertas características de una cultura de colectividad (su proximidad al eje de separación aún es muy grande). Esto significa que aunque predominantemente individualista, no se debe descartar estrategias comerciales dirigidas a los países con un cierto grado de colectividad cuando haya una oportunidad representada por individuos de la cultura argentina. Esta observación también puede ser administrada para Brasil y Uruguay, pero a contrario sensu. Estos países se encuentran en una situación muy cerca de Argentina, pero del otro lado de la frontera, cuando analizamos por separado la IDV.

La gran mayoría de los países de América Latina se ubican del lado de una mayor distancia del poder (culturas jerárquicas) y son en su totalidad los representantes de culturas con un alto grado de colectividad (tienen leyes que favorecen los intereses colectivos). Sucede que al observar que algunos países de manera más cuidadosa en relación al IDP, se puede verificar que Costa Rica es el único representante de América Latina que se encuentra en el cuadrante $B$. Esto significa que, aunque jerárquica, tiene una fuerte tendencia a la cooperación en el proceso de negociación, ya que es una cultura que rinde culto a la colectividad, no sólo el individuo. Los países por encima de la línea de corte y con los atributos de una cultura de favoritismo a las individualidades poseen tendencias a la 
confrontación delante de situaciones de conflicto. Cabe destacar, que este es el tipo de característica de sociedades eminentemente capitalistas.

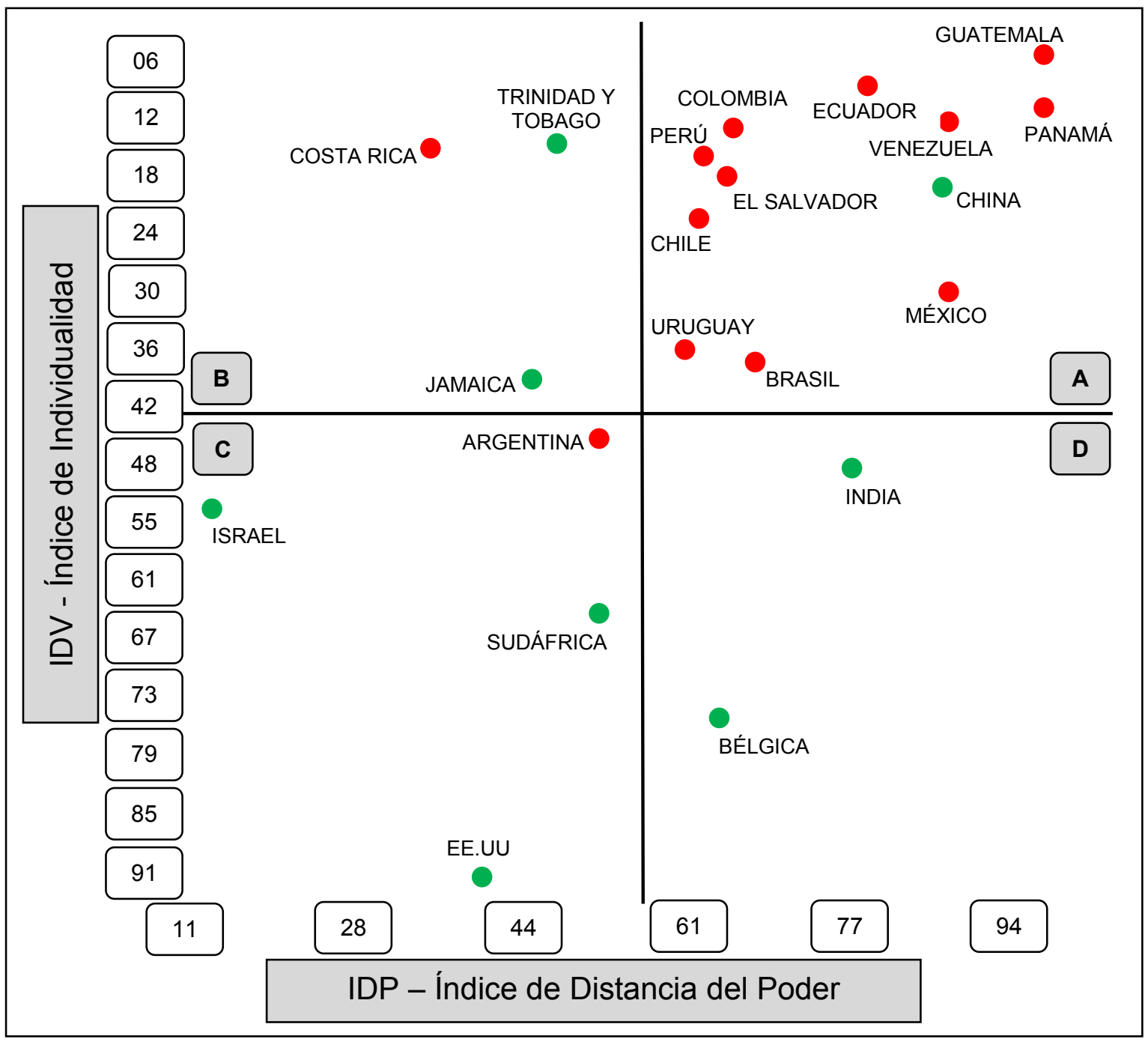

CUADRANTE A: Grande distancia del poder \& Baja individualidad

CUADRANTE B: Pequeña distancia del poder \& Baja individualidad

CUADRANTE C: Pequeña distancia del poder \& Alta individualidad

CUADRANTE D: Grande distancia del poder \& Alta individualidad

FIGURA N. 09 - POSICIONAMIENTO DE LOS PAÍSES EN RELACIÓN CON LOS ÍNDICES IDVIIDP

Fuente: Libre adaptación a partir de Hofstede ${ }^{51}$

${ }^{51}$ HOSTEDE. $(1980,2001)$ [9] 
Por medio de la Tabla . $^{\circ}$ 02, podremos verificar, en un formato resumido, las tendencias representadas por las intensidades de escala (alta o baja) en comparación con las diferentes dimensiones de cultura de Hofstede: ${ }^{52}$

TABLA N. 02 - MENSURACIÓN DE LAS DIMENSIONES CULTURALES DE HOFSTEDE

\begin{tabular}{|c|c|c|c|}
\cline { 2 - 4 } \multicolumn{1}{c|}{} & $\begin{array}{c}\text { Individualismo } \\
\mathbf{X} \\
\text { Colectivismo }\end{array}$ & $\begin{array}{c}\text { Igualitarismo } \\
\mathbf{X}\end{array}$ & $\begin{array}{c}\text { Alto X Bajo nivel de } \\
\text { conformidad en el contexto } \\
\text { de la comunicación }\end{array}$ \\
\hline $\begin{array}{c}\text { De alta } \\
\text { escala }\end{array}$ & $\begin{array}{c}\text { Crecimiento } \\
\text { personal }\end{array}$ & $\begin{array}{c}\text { Diferenciación social } \\
\text { (status jerárquico) }\end{array}$ & $\begin{array}{c}\text { Relaciones formales } \\
\text { (estructuras, normas e rituales) }\end{array}$ \\
\hline $\begin{array}{c}\text { En pequeña } \\
\text { escala }\end{array}$ & $\begin{array}{c}\text { Harmonía del } \\
\text { grupo }\end{array}$ & $\begin{array}{c}\text { Integración social } \\
\text { (status igualitario) }\end{array}$ & $\begin{array}{c}\text { Relaciones informales } \\
\text { (menos control) }\end{array}$ \\
\hline
\end{tabular}

Fuente: Libre adaptación a partir de Hofstede ${ }^{53}$ y Brett $^{54}$

\subsection{Las dimensiones de Schwartz}

Algunos años después de la obra publicada por Hofstede ${ }^{55}$, Shalom Schwartz, influenciado por las demandas del mercado y sensibles a las necesidades de sus clientes, propuso una relación un poco versátil y que aludió a siete categorías de valores de trabajo: jerarquía (dividido en dos subgrupos - tradición y conformidad), la armonía, el conservadurismo, el igualitarismo, la autonomía intelectual, la autonomía afectiva y el dominio. ${ }^{56}$

Tanto Hofstede como Schwartz juzgaban que sus trabajos se encajaban perfectamente en la línea de pensamiento funcionalista, de donde llegamos a la conclusión de que ambos trabajaron con la hipótesis de que las normas y los valores

\footnotetext{
${ }^{52}$ HOFSTEDE. $(1980,2001)[9]$

${ }^{53}$ Idem.

${ }^{54}$ BRETT. (2001, 2007) [2]

${ }^{55}$ HOFSTEDE. (1980) [9]

${ }^{56}$ SCHWARTZ. (1992, 1994, 1999) [21]
} 
sociales son los pilares de una sociedad, y por lo tanto también de sus organizaciones. Como resultado, se adopta un concepto de macro universal con el fin de proporcionar la clasificación de todas las sociedades en conformidad (tomando como base el mismo conjunto de características) y formando así un sistema de prioridad de valores. ${ }^{57}$

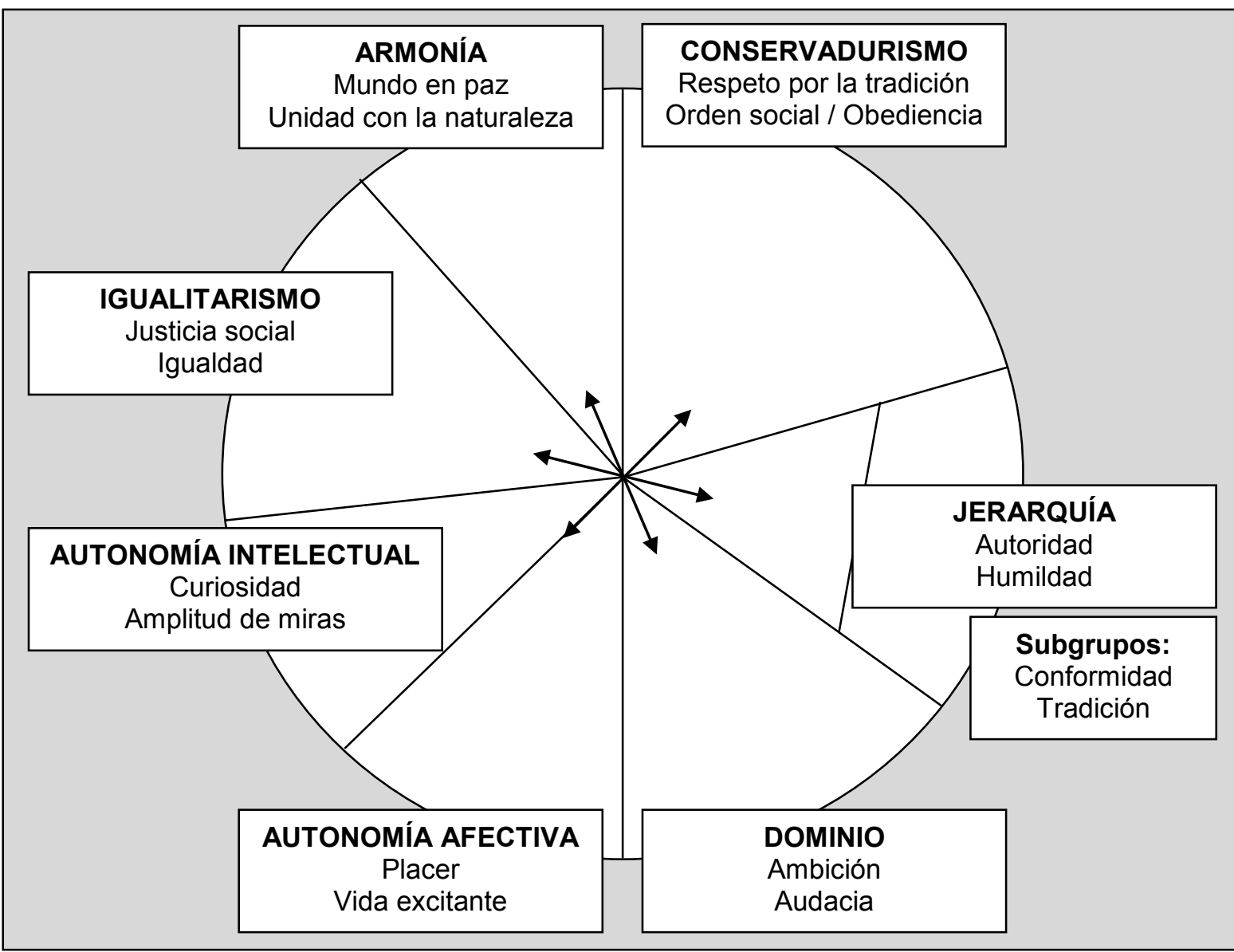

FIGURA N. ${ }^{\circ} 10$ - DIMENSIONES DE SCHWARTZ

Fuente: Libre adaptación a partir de Schwartz ${ }^{58}$

Schwartz define que los valores aquí recomendados sirven a los intereses de las entidades sociales. Implícitamente, pueden motivar acciones y dar a ellas direcciones e intensidad emocional.

\footnotetext{
${ }^{57}$ BEHRENS. (2008) [2]

${ }^{58}$ SCHWARTZ. $(1992,1994,1999)$ [21]
} 
Valores, como podemos observar en el Capítulo 1 de esta tesis, se adquieren y se forman posteriormente por experiencias únicas vividas por el individuo durante toda su existencia en un ambiente que se inserta en una colectividad.

Al inserir las referencias proporcionadas por los países en una matriz de dos dimensiones con las caracterizaciones propuestas por Schwartz, podemos observar el cambio hacia una mayor densidad de estándares (eje de las ordenadas) y a un mayor colectivismo (eje de las abscisas).

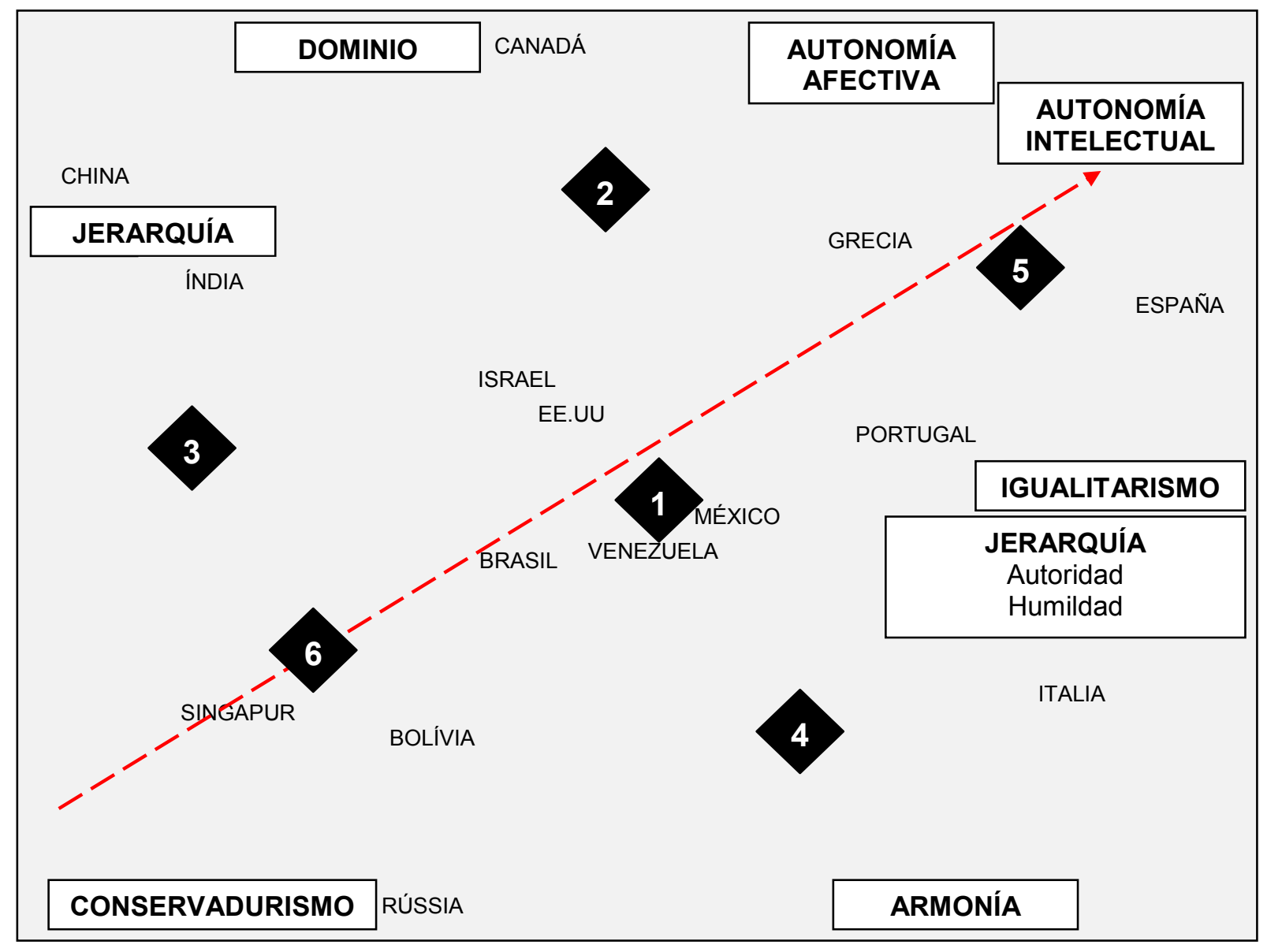

EPICENTROS:

[ 1 ] AMÉRICA LATINA [ 2 ] COLONIZACIÓN INGLESA [ 3 ] ASIA [ 4 ] EUROPA ORIENTAL [ 5 ] EUROPA OCCIDENTAL [ 6 ] ISLAM

FIGURA N. ${ }^{\circ} 11$ - MODELO DE SCHWARTZ

Fuente: Libre adaptación a partir de Schwartz ${ }^{59}$ 
En un análisis detallado de la Figura $n^{\circ} 11$ podemos ver que mientras más países se encuentran a la izquierda del cuadro, hay una mayor tendencia a la individualidad, es decir, acostumbran operar en un ambiente de competencia, oportunidades y recompensas individuales, mientras que los países situados a la derecha del cuadro, tienen una mayor tendencia al colectivismo, es decir, acostumbran operan en un entorno cuyos individuos se encuentran preocupados con los límites, las exclusiones, las reglas, la seguridad, la justicia y la participación. En la misma proporción, encontramos que cuanto más países se encuentran en la parte superior del cuadro, los entornos suelen ser más propensos a actitudes democráticas, por ejemplo, el sentimiento de responsabilidad para con la institución y con el prójimo, la equidad y la justicia social, y cuanto más los países se encuentran en la parte inferior del cuadro, por lo general acostumbran ser ambientes menos propensos a las actitudes democráticas, es decir, papeles asignados mediante definiciones claras (la edad o el sexo, por ejemplo), por el linaje o por posicionamiento.

En resumen:

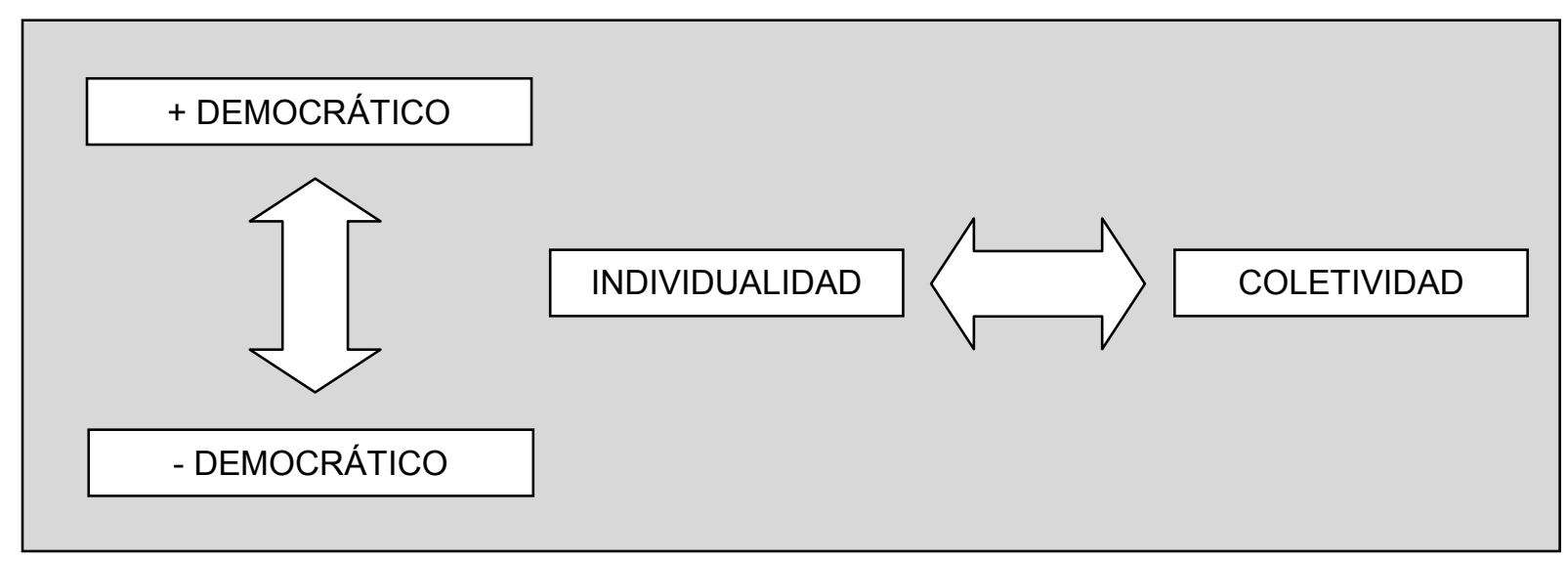

FIGURA N. 12 - EVOLUCIÓN DE LAS FUERZAS DE SCHWARTZ

Fuente: Libre adaptación a partir de Schwartz ${ }^{60}$ 


\section{CARACTERÍSTICAS DE LOS NEGOCIADORES DE LOS PRINCIPALES PAÍSES DE AMÉRICA LATINA}

\subsection{Una visión general}

En un análisis puro, las personas son similares en todas partes. Invariablemente, individuos quieren ser amados y reconocidos por sus méritos. Son preocupados con la consideración de los demás así como de ellos mismos. Por otra parte, en un análisis algo más complejo, somos seres totalmente diferentes. Algunos son reservados, otros expansivos, algunos son conservadores, otros tienen que someterse a los riesgos para sentirse vivo (mismo que calculados), algunos son rápidos y directos, sin gastar demasiado tiempo en detalles, otros son diplomáticos y utilizan el tiempo como un aliado para tomar decisiones de la mejor manera posible. No existe una fórmula para lo que es correcto o errado cuando se trata de negociación, pues mientras negociadores, personas diferentes revelarán intereses y estilos de comunicación diferentes. ${ }^{61}$ Un gran número de negociadores prefieren ser considerados como individuos únicos. Los estereotipos que existen en la actualidad pueden estar muertos en un futuro no muy lejano. Por lo tanto, ¿cómo conciliar las diferencias y similitudes al negociar con personas de diversas culturas en América Latina?

La intención de los próximos temas de esta tesis no es el de promover estereotipos sociales, mucho por el contrario. Se tienen en cuenta que el objetivo de este trabajo es demostrar las habilidades de negociación que funcionen sobre las más variadas formas de manifestación.

Al preparar una lista de características genéricas de las diferentes culturas, el objetivo final es demostrar un medio por el cual podemos exponer las creencias culturales de los distintos grupos de las sociedades latinoamericanas y alertar para evitar malos entendidos, trayendo beneficios mutuos a las partes involucradas en las negociaciones interculturales.

\footnotetext{
${ }^{61}$ FISHER, URY y PATTON. (1994) [5]
} 


\subsection{Argentina}

Argentina es un país de proporciones continentales que mezcla una fuerte herencia cultural europea con tradiciones rurales regionalistas. ${ }^{62}$ La tasa de alfabetización total para jóvenes de 15 a 24 años de edad es de $99,2 \%{ }^{63}$ De los quince premios Nobel distribuidos para América Latina hasta la actualidad, cinco fueron argentinos. ${ }^{64}$ Los niveles educacionales de ese país se comparan a los del primer mundo y apenas los conturbados acontecimientos contemporáneos en el sector político, alejaron al país de su pleno desarrollo.

Negociadores argentinos son fuertemente influenciados por los sentimientos de formalidad y orgullo de su pasado histórico. Son cultos y educados. Sin embargo, buscan una relación personal en la búsqueda de cerrar un trato. Comúnmente, interrumpen diálogos con el fin de poner en práctica las preguntas y observaciones. Son eficientes y no suelen darse por vencidos fácilmente. Migran de la formalidad a la informalidad rápidamente, pero hasta que eso ocurra, se debe respetar códigos de conducta locales. Tienen una tendencia a profundizar contratos y documentos, por ejemplo, no clocar todas las cuestiones por escrito puede ser ofensivo para el proceso de negociación. Conocer personas influyentes y la cultura es un factor crítico de éxito para negociar con argentinos. Construir una sociedad con un representante argentino puede significar un negocio con longevidad.

En la Figura n. ${ }^{0} 13$ puede verificarse una encuesta a una muestra de ejecutivos argentinos que enumeraron los principales atributos al negociador argentino. De acuerdo con su saber y entender, el negociador argentino es especialmente desconfiado $(52 \%)$, muy poco paciente $(3 \%)$ y modesto $(1 \%)$, pero por suerte, también es considerado hábil (46\%).

\footnotetext{
62 Solamente Buenos Aires, hasta 1895, recibió cerca de 600 mil inmigrantes europeos. Casi mitad de su población era proveniente de otro país. [28]

${ }^{63}$ CEPAL - Comisión Económica para América Latina y el Caribe. (2010) [23]

${ }^{64}$ Organización NOBEL PRIZE [33]
} 


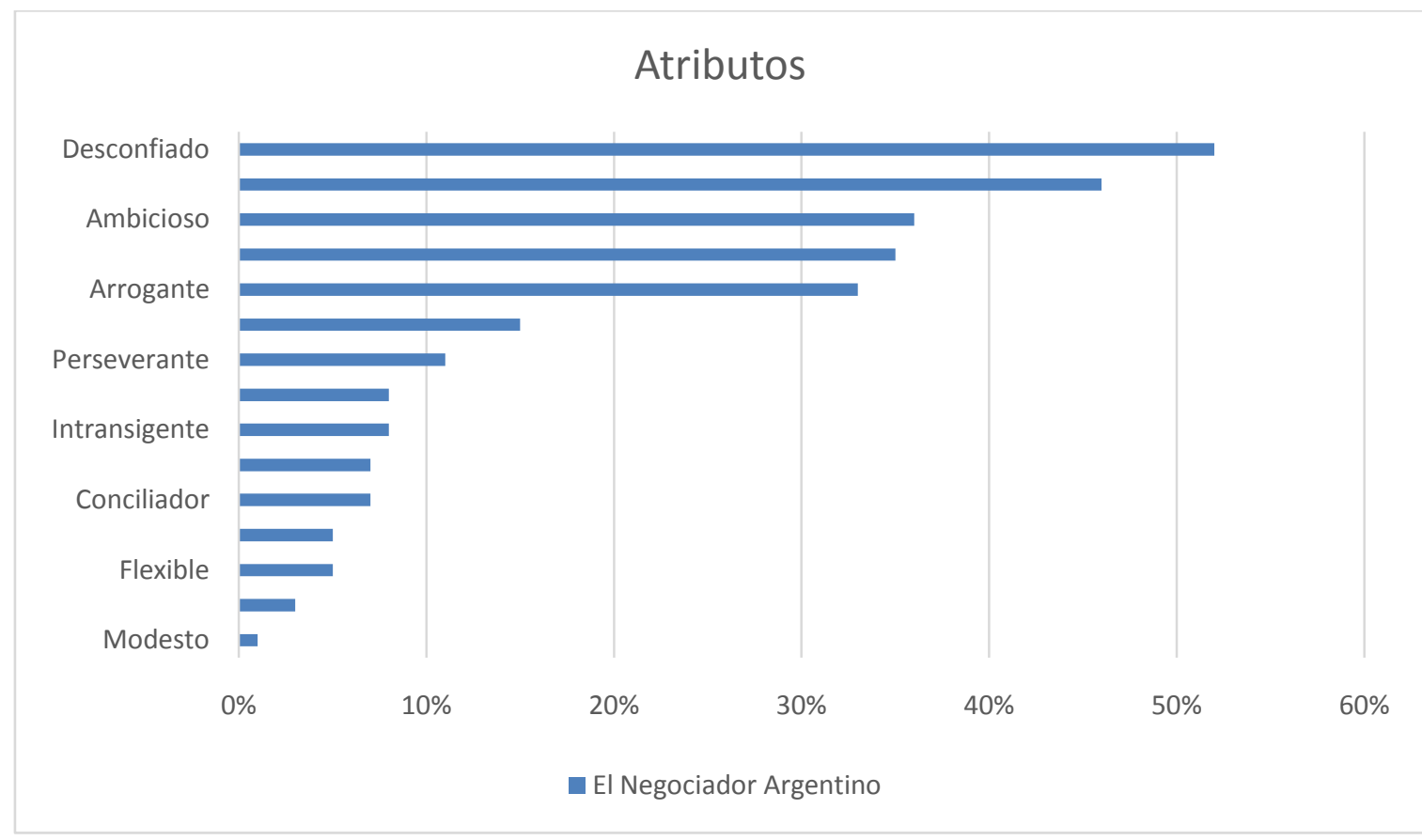

FIGURA N. 13 - ATRIBUTOS DEL NEGOCIADOR ARGENTINO

Fuente: Libre adaptación de Luchi, Zamprile y Luzuriaga ${ }^{65}$

\subsection{Brasil}

El gigante Brasil es un país que concentra una variación étnica muy compleja, resultado de su pasado histórico, pues fue poblada sirviendo de válvula de salida social al pueblo portugués. Por lo tanto, dando una segunda oportunidad a los malhechores e indeseados, sus tierras juntaron europeos, indios nativos y más tarde una gran masa de negros de África. Es un país muy poblado, aunque escasamente poblada $^{66}$ y tiene una tasa de pobreza en $20,9 \% .{ }^{67}$ Tiene en la agroindustria su principal producto, actividad que representa $22 \%$ de su $\mathrm{PIB} .^{68} \mathrm{El}$ país lidera en productividad agrícola en América Latina y Caribe con media de crecimiento en 3,6\%

\footnotetext{
${ }^{65}$ LUCHI, ZAMPRILE y LUZURIAGA. (2005) [11]

${ }^{66}$ Casi 200 millones de personas de menos de 20 habitantes $/ \mathrm{km}^{2}$. IBGE - Instituto Brasileiro de Geografia e Estatística. (2013) [31]

${ }^{67}$ CEPAL - Comisión Económica para América Latina y el Caribe. (2011) [23]

${ }^{68}$ OECD - Organization for Economic Co-operation and Development. (2012) [34]
} 
al año. ${ }^{69}$ Sin embargo, es una nación que sigue la búsqueda continua de su identidad nacional y hace de sus raíces mezcladas un fuerte elemento de autoestima.

Brasileños viven en un ambiente donde la excepción a la regla es la regla, por lo que todo profesional brasileño tiende a ser creativo, innovador y con habilidad para salir de situaciones complicadas. Eludir las dificultades y crear soluciones irreflexivas son parte del día a día del negociador brasileño. Son hospitalarios y no suelen ser formales, sólo cuando el protocolo lo requiere. Se conocen como buenos oyentes, atentos y conciliadores. Son comúnmente seleccionados para mediar situaciones de arbitraje o para el cargo de observador técnico internacional debido a estas características.

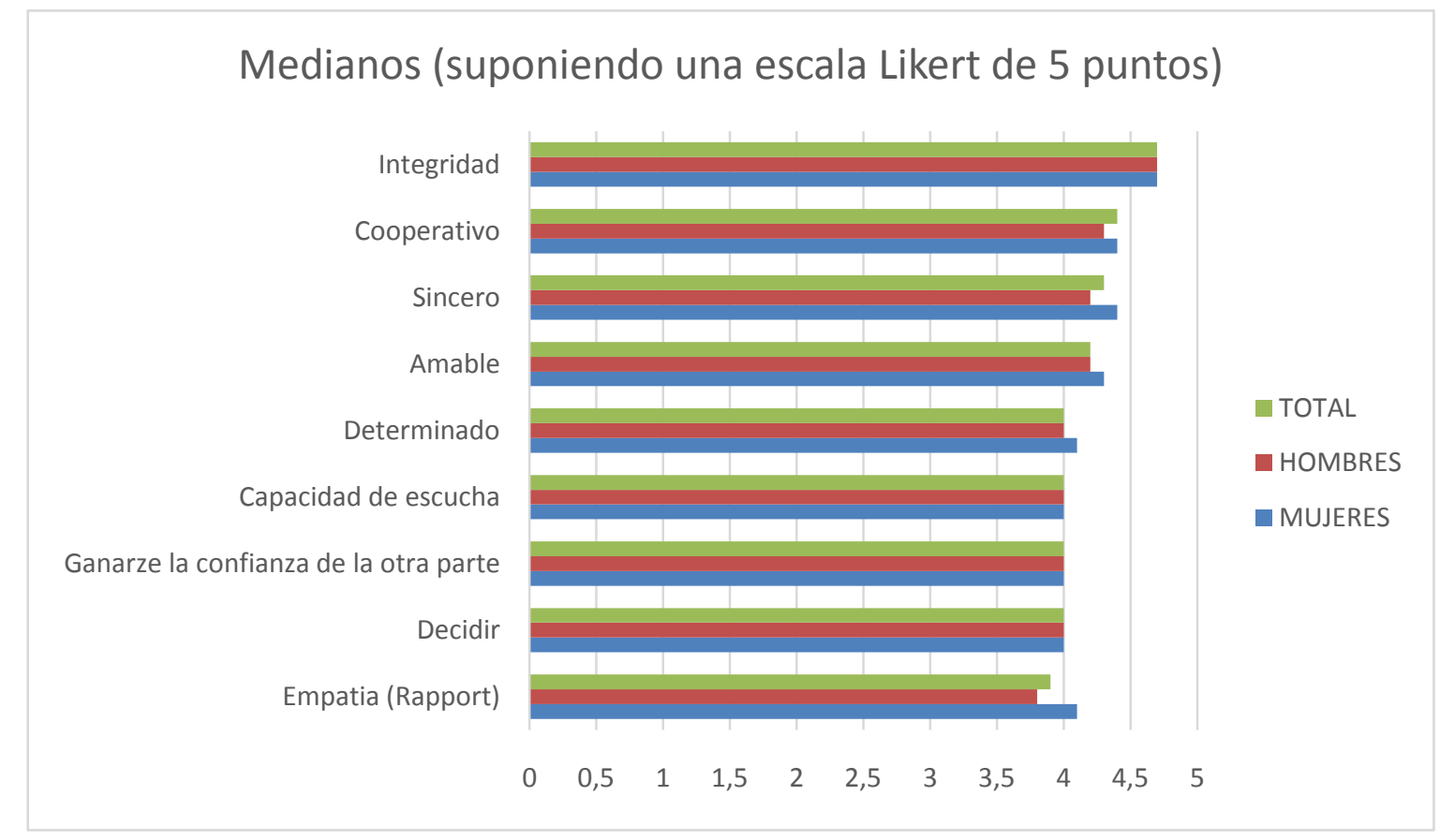

FIGURA N. ${ }^{\circ} 14$ - CARACTERÍSTICAS DE LOS NEGOCIADORES BRASILEÑOS

Fuente: Libre adaptación de Carvalhal ${ }^{70}$

\footnotetext{
${ }^{69}$ OECD - Organization for Economic Co-operation and Development. (2012) [34]

${ }^{70}$ DO CARVALHAL et al. (2006) [3]
} 
La investigación relacionada en la Figura n. ${ }^{\circ} 14$ se llevó a cabo durante cuatro años con la participación de 4.248 negociadores de diferentes partes de Brasil. Teniendo en cuenta las características que influyen positivamente en el rendimiento de las personas en situaciones de negociación, los negociadores brasileños (divididos en hombres y mujeres), en una lista de 40 características posibles, escogieron igualmente como la más importante la integridad (la equidad y la justicia).

\subsection{Chile}

Geográficamente, Chile posee una forma bien diferente. Ocupa una distancia máxima vertical de 4.329 kilómetros y es responsable por la mayor extensión de tierra en el litoral pacífico de América del Sur. ${ }^{71}$ En función de eso, es considerado como una importante ruta de comercio internacional. Líder en América Latina cuanto al Índice de Desarrollo Humano, ${ }^{72}$ posee una gran industria pesquera y se estima que posee casi un tercio de las reservas cupríferas del planeta. ${ }^{73}$ Además de eso, el país está localizado sobre la placa tectónica de Nazca, lo que dio como resultado en el terremoto con mayor intensidad, desde el Siglo XX. ${ }^{74}$

Pueblo que tiene una historia política con problemas, sin embargo los chilenos son poseedores de un gran sentido del humor y adoran el contacto físico mismo con extraños. Apretón de manos, un beso en la mejilla y relación ojo en el ojo: es el secreto de los negociadores chilenos. La cercanía y la intimidad de las conversaciones pueden asustar a los más conservadores. Por lo general, hacen invitaciones para que la otra parte frecuente sus hogares. Ser un entusiasta y expresarse bien son condiciones esenciales para la negociación de una buena asociación.

\footnotetext{
${ }^{71}$ IBGE - Instituto Brasileiro de Geografia e Estatística. (2012) [31]

${ }^{72}$ El IDH es promovido por el PNUD - Programa de las Naciones Unidas para el Desarrollo. [35]

${ }^{73}$ CEPAL - Comisión Económica para América Latina y el Caribe. (2011) [23]

${ }^{74}$ Sismo de Valdivia, el 22 de Mayo de 1960.
} 


\subsection{Cuba}

Décima sexta mayor isla del mundo, la principal y mayor extensión territorial del archipiélago de Cuba, posee clima tropical templado con vientos alisios y una media de humedad relativa del aire en $81 \% .{ }^{75}$ En los últimos cincuenta años, Cuba redujo drásticamente el índice de mortalidad infantil para niños de hasta 5 años de edad y desarrolló un sistema de salud eficaz donde, por ejemplo, 95\% de la población infectada por el virus del SIDA posee acceso gratuito a medicamentos. ${ }^{76}$ EI país también posee una buena industria exportadora de materias-primas y una gran carencia de importaciones. ${ }^{77}$

La población cubana es educada y culta. Su gran mayoría tiene títulos universitarios. Los negociadores valoran el contacto físico, sobre todo cuando se quiere resaltar algún momento de la conversación. Cambios de asuntos e interrupciones en las negociaciones son muy comunes. Las burocracias del sistema cubano son complicadas. Como resultado, es comúnmente necesario conocer algunos interlocutores locales para ayudar en los procesos de negociación relacionados con la documentación por escrito y que se pierde mucho tiempo negociando un plazo factible para todo el proceso.

\subsection{México}

La economía mexicana creció mucho después del ALCA y ese detalle influenció el país a adoptar el inglés para poder comercializar en mayor escala. Más de $90 \%$ del comercio exterior mexicano está protegido en el formato de acuerdos de libre comercio con 44 países. ${ }^{78}$ Geográficamente es un país de altos contrastes y cuenta con cerca de 600 áreas de preservación ambiental. La tasa de población indigente

\footnotetext{
${ }^{75}$ UNESCO - United Nations Educational, Scientific and Cultural Organization. (2013) [36]

${ }^{76}$ CEPAL - Comisión Económica para América Latina y el Caribe. (2010) [23]

${ }^{77}$ MARTINELLI, VENTURA y MACHADO. (2011) [13]

${ }^{78}$ ALCA - Área de Libre Comercio de las Américas [22]
} 
es de $13,3 \%$ del país (siendo que $8,5 \%$ solamente en área urbana) y $12,4 \%$ de la población femenina ya tuvo al menos un hijo entre 15 y 19 años de edad. ${ }^{79}$

Su fuerte diversidad cultural tiene raíces en el período pre-colonial con la combinación española. Orgullo mexicano es su origen Azteca, así como sus referencias culturales. Son un pueblo encantador, pero en la misma medida pueden ser impulsivos y violentos. Reuniones de negocios suelen ser muy informales y se gasta un relativo tiempo con asuntos preliminares. Evitar tratar con valores reducidos y negociar concesiones demostrará interés, porque los mexicanos tienen una tendencia a precios de ganga y plazos. Al negociador que hará negocio con mexicanos es importante incluir la mayor cantidad de informaciones posibles, ya que esto denotará honestidad.

\subsection{Venezuela}

La exuberancia geográfica venezolana es atestada por su vasta extensión territorial bañada por el Mar del Caribe, por sus montañas y planicies ricas en biodiversidad. Combustibles y sus derivados representan $75 \%$ de la pauta de exportación de ese país ${ }^{80}$ que recientemente se adhirió definitivamente al bloque comercial del Mercosur. ${ }^{81}$ Venezuela es considerada el país más urbanizado de América del Sur, donde $85 \%$ de la población vive en áreas urbanas en la parte norte del país. ${ }^{82}$ Más de dos millones de extranjeros viven en el país.

Los venezolanos son un pueblo de rica combinación hereditaria, compuesto por diversas etnias (las principales son: española, indígena y africana). Cláusulas al respecto de igualdad de género (hombre/mujer) fueron recientemente introducidas en sus convenciones colectivas de trabajo. ${ }^{83}$ Sus negociadores son hospitalarios y

\footnotetext{
${ }^{79}$ CEPAL - Comisión Económica para América Latina y el Caribe. (2010) [23]

80 Idem.

${ }^{81}$ MERCOSUR - Mercado Común del Sur. (2013) [32]

${ }^{82}$ CEPAL - Comisión Económica para América Latina y el Caribe. (2010) [23]

${ }^{83}$ Idem.
} 
humildes. La mayoría son jóvenes y orgullosos de pertenecer a su entorno. Por lo general, tienen la costumbre de negociar en grupo. Los intereses de la empresa o de la colectividad, por lo general están por encima de los intereses personales.

\section{FACTORES DE ÉXITO EN LAS NEGOCIACIONES INTERCULTURALES}

\subsection{Actitudes esenciales de un negociador internacional}

Nos dimos cuenta que, a través de esta tesis, el factor cultural es lo que más influye en las negociaciones internacionales. El simple hecho del negociador estar bien preparado, dispuesto y demostrar cómo tratar con diferentes costumbres no es una fórmula exacta para el éxito total de las negociaciones internacionales, pero son pasos simples que pueden optimizar sus posibilidades de éxito.

Por lo tanto, hemos enumerado a continuación algunas actitudes esenciales para cualquier individuo que se pone en una posición como negociador internacional:

TABLA N. ${ }^{\circ} 03$ - ACTITUDES ESENCIALES PARA EL NEGOCIADOR INTERNACIONAL

\begin{tabular}{|l|l|}
\hline \multicolumn{1}{|c|}{ QUE SE DEBE HACER } & \multicolumn{1}{c|}{ QUE NO SE DEBE HACER } \\
\hline Ser sensitivo a las costumbres locales & Parecer nativo \\
\hline Conocer el escenario político local & Envolverse en temas que no le pertenecen \\
\hline Respetar autoridades & Dejar a la otra parte esperando \\
\hline Estar siempre tranquilo y preparado & $\begin{array}{l}\text { Ser sorprendido con actos que podrían } \\
\text { haber sido previstos }\end{array}$ \\
\hline Salir y hablar con las personas & Sucumbir a las tentaciones locales \\
\hline $\begin{array}{l}\text { Tener compañeros de equipo educados } \\
\text { y que posean la virtud de agradecer }\end{array}$ & Intentar enseñar a otra parte \\
\hline Ser flexibles y aceptar cambios & $\begin{array}{l}\text { Insistir en un método personal para } \\
\text { realizar tareas }\end{array}$ \\
\hline Guardar documentos en seguridad & Demostrar su ego \\
\hline Saber oír & Imponer ideas propias preconcebidas \\
\hline Ser paciente & Dejar el territorio preservado \\
\hline
\end{tabular}

Fuente: Libre adaptación de Steel, Murphy y Russill ${ }^{84}$

${ }^{84}$ STEEL, MURPHY y RUSSILL. (1995) [17] 
Siempre desde nuestra óptica latinoamericana la observación que se hace es mucho más compleja porque las negociaciones se caracterizan por las diferencias que surgen en los niveles de comportamiento interpersonales, que en realidad son expresiones de diferencias sociales / institucionales mucho más profundas.

Actuando como describe la Tabla $N^{\circ}$. 03, el negociador internacional tiene lo mínimo necesario para participar en una situación de negocios a nivel internacional. En pocas palabras, estas personas deben aprender a reconocer las diferencias culturales con el fin de estar alerta para identificar las diferencias en valores, reconocer las diferentes concepciones del poder, evitar los estereotipos o errores de asignación, y, sobre todo, mostrar respeto a las culturas compartidas para estar seguro de proponer acuerdos buscando siempre el mejor formato de negociación posible.

\subsection{Indicadores de éxito para el negociador internacional moderno}

La siguiente lista se refiere a un compendio de habilidades deseables para componer el perfil del negociador internacional moderno. La relación proporciona una rápida revisión de su estado de espíritu y monitora cuan preparado él se encuentra en aquel momento para ejercer una determinada tarea. ${ }^{85}$ No es que el negociador necesite estar en completa función de estas capacidades en cada momento del proceso, sino dirigirlas como elementos para la optimización de los resultados. Es el momento clave en la ruta de oro para el éxito, por supuesto, con independencia de variables externas.

Funciona prácticamente como un check-list compuesto por 25 artículos:

- Paciencia (negociaciones pueden ser rápidas, pero en la mayoría de las veces precisan de tiempo para la madures de las decisiones);

- Prevención (programar compromisos con plazo denota educación y menos sobrecarga, además del hecho de que ambas las partes tendrán más tiempo para una mejor planificación de la negociación);

${ }^{85}$ THOMPSON. (2009) [18] 
- Transparencia (no prometer lo que no se puede cumplir y documentar correctamente todas las etapas de la negociación);

- Complexidad conceptual (visión holística del proceso y de sus resultados);

- Categorización amplia (poder de ajustarse a ambientes modificados o restrictos);

- Empatía (establecimiento de rapport, espejarse y saber colocarse en el lugar de la otra parte);

- Sociabilidad (educación, conocimiento general y respeto; además del hecho que el negociador debe ser capaz de reconocer lo más rápido posible las probables diferencias culturales de la otra parte con el intuito de ganar tiempo en la construcción de un proceso de empatía);

- Político (cuando el asunto sugerir cualquier tipo de polémica - religión, regímenes de gobierno, deportes o cualquier otro asunto que provoque discusiones acaloradas - ser imparcial o hasta mismo omitir prestar opiniones personales o referentes a su institución);

- Visión crítica sobre estereotipos (aceptación de los estereotipos cuando la situación permitir, pero siempre recordarse que sirve como una orientación para el proceso de negociación y no como regla);

- Timing (sentir el momento correcto para abordar, proponer y recusar acciones)

- Open mind (apertura a diferentes puntos de vista);

- Respeto, interés y sensibilidad por la(s) cultura(s) de la(s) otra(s) parte(s) (mismo cuando la otra parte no demuestre el mismo tipo de respeto, interés y sensibilidad por parte de su cultura o de su empresa);

- Orientación social (capacidad de establecer, mantener nuevos contactos y encontrar un punto de confluencia cultural);

- Buena voluntad en comunicarse en la lengua ajena (no significa obtener fluidez en el habla y la ortografía, pero sí en expresar interés aprendiendo gestos y palabras claves con el propósito de aproximarse); 
- Flexibilidad (estar siempre pronto para imprevistos y poseer aptitud para estudios o trabajos en diversas áreas);

- Organización y gestión de sus procesos / tareas;

- Tolerancia (saber perdonar pequeños deslices, tener complacencia);

- Business (nunca colocar intereses personales por encima de los intereses reales de negocio);

- Habilidad diplomática (en la conducción de los procesos, en el tratamiento con el prójimo y en reuniones);

- Idoneidad (estar apto para desarrollar la función a la que se destina);

- Creatividad (dentro de sus posibilidades, proponer resolución participativa para conflictos de diferentes naturalezas);

- Censo de humor (moderado, siempre sujeto al ambiente y momento de la negociación);

- Credibilidad (se construye con el tiempo, pero la conducción de una comunicación no verbal correcta puede corroborar con la idea de ética y credibilidad);

- Receptividad (saber oír y aceptar sugestiones);

- Energía (tomar decisiones correctamente, demostrar agilidad, salud y sagacidad).

Varias investigaciones recientes en empresas de diversos países del mundo, así como los informes sobre libros y publicaciones periódicas, reportan que más de dos tercios de éxito profesional y personal se debe a la competencia emocional, mientras que sólo un tercio se verifica mediante la preparación cognitiva y técnica del cual se ocupan las fuentes: las escuelas de formación. Otro hecho importante es que cuanto mayor es la responsabilidad del ejecutivo en un cargo o en una negociación, mayor será la demanda subrayada por la competencia emocional. ${ }^{86}$

\footnotetext{
${ }^{86}$ GOLEMAN. (2013) [8]
} 
Por lo tanto, estamos delante de desafíos extremamente complejos. En relación al macro ambiente de una negociación es hoy imprescindible tomar conocimiento de las características culturales particulares de cada mercado antes de actuar en él. En cuanto al entorno personal, la preparación y el desarrollo de las habilidades necesarias para manejar adecuadamente las diversas situaciones es un arte. El arte de la negociación internacional intercultural moderna. Un trabajo destinado para pocos.

\section{Conclusiones}

\subsection{Conclusiones propiamente dichas}

América Latina del siglo XXI es muy similar y al mismo tiempo muy diferente. Está lejos de ser considerada un bloque geográfico, a pesar de tener muchos códigos arraigados de conducta y antecedentes similares. Los latinoamericanos son diferentes en muchos aspectos, pero tienen una amplia base ideológica y antigua. El sudor, la sangre y la pobreza marcaron la historia de todos esos pueblos y la sensación de una unidad latinoamericana es hoy en día una línea muy fina para los retos de una nueva era.

Los trabajos sobre cultura política descrito en esta tesis fueron históricamente responsables por los primeros enfoques coherentes que influyeron en la comprensión de la coexistencia de más de un tipo de cultura dentro de un área geográficamente delimitada, así como pudieron demostrar que sus diferencias están directamente relacionadas con la intensidad que la cultura de un grupo prevalece sobre las demás. Todos los ejemplos aquí trabajados permiten que nos centremos en los grupos de individuos que manifiestan actitudes hacia el colectivismo y construyen el carácter nacional de un país. Estos países, que asentían en la realización de comparaciones interculturales dentro del continente latinoamericano impulsan implicaciones en el ámbito de la gestión mundial - en nuestro caso, precisamente en el área de marketing internacional. 
Debemos repensar las prácticas de gestión en América Latina y, sobre todo, para ajustarlos a las culturas de sus pueblos. No hay, hoy en día, camino para la aplicación de una solución armoniosa. Se deben respetar los valores y estudios locales en lugar de desecharlos, por medio de la adopción de las culturas de otros países. La solución está dentro de casa y puede ser aplicada con diferentes intensidades y medidas para los diferentes países. Después de todo, los sistemas que tengan en cuenta sus antecedentes culturales tienen una alta probabilidad de éxito.

La posibilidad de un acuerdo es siempre implícita en una negociación, pues partimos de la premisa que si las partes están dialogando, existe una buena intención en ajustar el problema y llegar a un consenso. Cuando no se puede usar la negociación como un recurso para resolver un problema, es muy probable que una de las partes tenga que recurrir a los recursos legales o contractuales, lo que en niveles internacionales, en particular, es un situación compleja y onerosa.

Los buenos negociadores deben actuar evitando las acciones defensivas o cualquier otro tipo de comportamiento que impiden un acuerdo pacífico y por lo tanto, la resolución del conflicto. También es fundamental que operen constantemente en la creación, el mantenimiento y la expansión de su credibilidad. Encuestas recientes muestran que el $90 \%$ de éxito de una negociación está indirectamente relacionada con el factor suerte y cada vez más centrado en la figura humana: el negociador. Por lo tanto, para comunicarse adecuadamente, enviando mensajes claros y precisos, saber escuchar y promover el tiempo para que las situaciones se encajen perfectamente, combinar bien su planificación de acuerdo con su línea de ejecución (si es posible, con un alto grado de maniobrabilidad), además de optimizar la oportunidad de contacto para establecer una relación correctamente, manteniendo así un cierto atractivo en relación a otra parte, son actitudes esenciales para promover una negociación exitosa.

Hacer suposiciones sobre cualquier individuo teniendo como referencia sus características del grupo (empresarial, social, étnica, geográfica etc.) es insultante. Además de tremendamente arriesgado. Antes de todo, usted estará negando su individualidad y posiblemente creando errores de atribución. No se puede suponer que las culturas y las creencias sean dictadas por los grupos a los cuales los 
pertenecen los individuos, aunque estas informaciones sirven como prueba. Cada uno de nosotros se ve influenciada por un gran número de grupos culturales a los que pertenecemos, pero no siempre de manera individualmente previsible. Tener sensibilidad, respeto e interés por las costumbres y variaciones culturales que tratamos en una situación de negociación es fundamental para relaciones duraderas y rentables.

Lengua y cultura son y serán siempre conectados. La primera impresión fuerte puede garantizar una buena relación desde el principio. Esto se determina a través de una comunicación visual asertiva, representado por el uso adecuado de ropas, peinados, respetar las tradiciones (por ejemplo, un pañuelo que cubre la cabeza de las mujeres en los países musulmanes), entre otros; el toque, que pueden ser débil, moderado o fuerte, y puede significar la forma en que la negociación puede llevarse a cabo; la correcta comunicación con las miradas, pues desviaciones al mirar pueden ser considerados como un signo de falta de honradez; y por supuesto la comunicación verbal que no puede ser visto como un obstáculo para la negociación.

Las culturas tienen tendencias individualistas, definiendo a las personas por sus posiciones, logros y los lugares de trabajo o de residencia, así como las tendencias colectivistas que hacen hincapié en las relaciones entre individuos. Sin embargo no hay que olvidarse que algunas empresas se comportan como pequeñas representaciones de una cultura más amplia. Por lo general, este tipo de empresas utiliza la jerga específica de su negocio y el respeto de sus valores (o valores de sus fundadores). Sin embargo una empresa que no consigue nivelar culturalmente a sus empleados tiene una fuerte tendencia a tener una gestión complicada. Por lo tanto, hay desperdicio de recursos, infelicidad generalizada y reducción de la productividad. Aceptar las culturas forma parte de un proceso continuo y sensible a muchas variables. Los cambios toman tiempo. El tiempo significa dinero en el mercado.

En resumen, ante el marco expuesto a lo largo de estas páginas, lo que se buscó demostrar fue que la nueva realidad económica mundial es un hecho y, en consecuencia, solucionar conflictos de una forma pacífica, ética y eficaz se convirtió en la base de los procesos en las negociaciones, ya sean comerciales, de negocios o diplomáticas. Alentar el perfeccionamiento profesional, la formación y el 
aprendizaje de diferentes lenguajes son factores esenciales a los negociadores que quieren perforar las barreras culturales y llegar a nuevas alturas.

Sin embargo, continua la búsqueda por la innovación con la utilización de métodos creativos también es una constancia en el modelo de gestión internacional, lo que garantiza a las empresas a crear ventajas competitivas y su supervivencia en un mercado con las normas veloces y mutables. Estamos atentos a este nuevo ciclo de cambios en el mundo de los negocios y eso sólo nos hace que nos fortalezcamos cada vez más a lo que vinimos a buscar a través de esta tesina: una manera de cada vez más entender y optimizar la eficacia de las negociaciones interculturales.

\subsection{Próximos pasos}

Entender cuál es la relación exacta entre la formación profesional, la experiencia y el desarrollo de una persona física para ejercer un trabajo de negociación intercultural es un paso esencial para que cualquier individuo pueda desarrollar una técnica eficaz que pueda adaptarse a diferentes situaciones de conflicto. Para permitir esto, es importante que el negociador esté plenamente enterado sobre los escenarios internos y externos de la negociación y posea medios de impulsar sus habilidades en la consecución de los objetivos de la institución que él representa.

El ámbito de esta tesina es, básicamente, la promoción de la importancia de la comprensión y el respeto de las diferentes formas de expresiones culturales en América Latina, que buscan una mayor tasa de éxito en las negociaciones internacionales e interculturales proporcionando automáticamente la prevención de la pérdida de recursos y una mayor productividad. En una perspectiva a corto plazo, una posible ampliación de este trabajo sería llevar a cabo un plan de acción en formato de hoja de ruta para las negociaciones interculturales en América Latina. La tesis que tenemos en manos ofrece todo el apoyo para este tipo de propuesta. Sin embargo, ya en un largo plazo, a la vez que aumenta la gama geográfica analizada y llevar el mismo análisis del perfil y las características culturales de una dimensión global, también sería importante absorber una mayor cantidad de teorías sobre las formaciones de diferentes culturas para amplificar el poder de análisis acerca de los métodos de negociación. 
Un aspecto importante de este desarrollo posible y futuro es que los beneficios, aunque relativamente difíciles de ser medidos de manera objetiva, son fácilmente percibidos en el cotidiano de las ronda de negociaciones, y como consecuencia, en sus resultados. Comúnmente, estas negociaciones estarán vinculadas a las operaciones comerciales de forma general - incluso a diario - o a proyectos específicos. 


\section{BIBLIOGRAFÍA Y FUENTES CONSULTADAS}

[1] BEHRENS, Alfredo. (2008) Cultura e administração nas Américas: Perspectivas e tendências. São Paulo - Brasil. Editorial Saraiva. $1^{\text {a }}$ Edición.

[2] BRETT, Jeanne M.

(2001) Negotiating globally: How to negotiate deals, resolve disputes and make decisions across cultural boundaries. New York - USA. John Willey \& Sons. $1^{\text {a }}$ Edición.

(2007) Negotiating globally: How to negotiate deals, resolve disputes and make decisions across cultural boundaries. New York - USA. John Willey \& Sons. $2^{\text {a }}$ Edición.

[3] CARVALHAL, Eugenio do; NETO, A. Antônio; de ANDRADE, M. Gersem y de ARAÚJO, V. João. (2006) Negociação e administração de conflitos. Rio de Janeiro - Brasil. Fundação Getulio Vargas. $1^{a}$ Edición.

[4] CARVALHAL, Eugenio do. (2001) Negociação fortalecendo o processo: Como construir relações de longo prazo. Rio de Janeiro - Brasil. Editorial Vision. $1^{\text {a }}$ Edición.

[5] FISHER, Roger; URY, William y PATTON, Bruce. (1994) Como chegar ao sim: A negociação de acordos sem concessões. Rio de Janeiro - Brasil. Editorial Imago. $2^{\text {a }}$ Edición.

[6] GALEANO, Eduardo. (2011) As veias abertas da América Latina. Porto Alegre - Brasil. Editorial L\&pm. $1^{\text {a }}$ Edición. $3^{a}$ Reimpresión.

[7] GNAZZO, Liliana E.; LEDESMA, Carlos A.; DOMINGUEZ, Mirta; ELASKAR, Luis; ESPINA, Javier R.; OCHOA, Raúl V.; PEÑA, Gonzalo D. y URDANIZ, Fernando. (2007) Gestión de los negocios internacionales. Buenos Aires Argentina. Prentice Hall - Pearson Education. $1^{\text {a }}$ Edición.

[8] GOLEMAN, Daniel. (2013) Inteligencia emocional. Ciudad de México México. Ediciones B. $1^{\text {a }}$ Edición.

[9] HOFSTEDE, Geert.

(1980) Culture's consequences: International differences in work-related values. Thousand Oaks - USA. SAGE Publications, Inc. $1^{\text {a }}$ Edición.

(2001) Culture's consequences: International differences in work-related values. Thousand Oaks - USA. SAGE Publications, Inc. $2^{\text {a }}$ Edición.

[10] LEDESMA, Carlos A. y DOMÍNGUEZ, Mirta. (in the press) Introducción a la gestión intercultural de los negocios: De la cultura personal a la organizacional. Ciudad de México - México. Pearson Education. $1^{\text {a Edición. }}$

[11] LUCHI, Roberto; ZAMPRILE, Alejandro y LUZURIAGA, Nicolás. (2005) EI arte de negociación posicional: Como adaptar el traje a la medida de cada situación. Buenos Aires - Argentina. Temas Grupo Editorial. $3^{a}$ Edición.

[12] LUECKE, Richard. (2003) The Harvard Business essentials series: Negotiation. Boston - USA. Harvard Business School Press. $1^{\text {a }}$ Edición. 
[13] MARTINELLI, Dante P.; VENTURA, Carla A. A. y MACHADO, Juliano R. (2011) Negociação internacional. São Paulo - Brasil. Editorial Atlas. $1^{a}$ Edición. $2^{a}$ Reimpresión.

[14] PARÍS, José Antonio. (2010) Negocios internacionales desde Latinoamérica. Buenos Aires - Argentina. Errepar. $1^{\text {a }}$ Edición.

[15] POWELL, Mark. (2012) Cambridge business skills: International negotiations student's book with audio CD's. Cambridge - U.K. Cambridge University Press. $1^{\text {a }}$ Edición.

[16] SPARKS, B. Donald. (1992) A dinâmica da negociação efetiva: Como ser bem-sucedido através de uma abordagem ganha-ganha. São Paulo Brasil. Nobel. $1^{\text {a }}$ Edición.

[17] STEEL, P.; MURPHY, J. y RUSSILL, R. (1995) It's a deal: A practical negotiation. Berkshire - U.K. McGraw-Hill. $2^{a}$ Edición.

[18] THOMPSON, Leigh L. (2009) O negociador. São Paulo - Brasil. Prentice Hall - Pearson Education. $3^{\text {a }}$ Edición.

\section{ARTÍCULOS}

[19] ACKOFF, L. Russel. (1996) On pairs and trios: The smallest social systems. Systems Research. Volume 13: 435-446. doi: 10.1002/(SICl)1099-1735 (199612)13:4<435::AID-SRES64>3.0.CO;2-Q

[20] SCHMIDT, Stuart M. y KOCHAN, Thomas A. (1972) Conflict: Toward conceptual clarity. New York - USA. Administrative Science Quarterly. Volume 17: 3. Johnson Graduate School of Management, Cornell University

[21] SCHWARTZ, Shalom H. (1999) A theory of cultural values and some implications for work. Applied Psychology: An International Review. Volume 48: 23-47. doi: 10.1111/j.1464-0597.1999.tb00047.x

\section{PÁGINAS WEB}

[22] ALCA - ÁREA DE LIBRE COMERCIO DE LAS AMÉRICAS. Último acceso en 21/05/2013.

http://www.ftaa-alca.org/

[23] CEPAL - COMISIÓN ECONÓMICA PARA AMÉRICA LATINA Y EL CARIBE. Último acceso en 09/07/2013.

http://www.eclac.org

[24] EDITORA ABRIL. Revista Mundo Estranho. Último acceso en 10/12/2012. http://mundoestranho.abril.com.br/materia/quem-foram-os-incas-os-maias-e-osastecas 
[25] EJÉRCITO BRASILEÑO. Misión de paz del Gobierno de Haití. Último acceso en $02 / 12 / 2012$.

http://www.exercito.gov.br/web/hait//historico

[26] GOBIERNO DE BELIZE. Último acceso en 15/07/2013.

http://www.belize.gov.bz/

[27] GOBIERNO DE CANADÁ. Último acceso en 02/02/2013.

http://www.canadainternational.gc.ca/

[28] GOBIERNO DE LA REPÚBLICA ARGENTINA. Último acceso en 20/10/2012. http://www.argentina.gob.ar/

[29] GOBIERNO DE LA REPÚBLICA FEDERATIVA DEL BRASIL. Último acceso en 20/10/2012.

http://www.brasil.gov.br/

[30] GRUPO RENAULT-NISSAN. Último acceso en 15/07/2013.

http://www.renault.com.br/mais_renault/alianca_renault_nissan

[31] IBGE - INSTITUTO BRASILEIRO DE GEOGRAFIA E ESTATÍSTICA. Último acceso en 31/03/2013.

http://www.ibge.gov.br/

[32] MERCOSUL - MERCADO COMUM DO SUL. Último acceso en 12/02/2013.

http://www.mercosul.gov.br/

[33] NOBEL PRIZE ORGANIZATION. Último acceso en 15/01/2013.

http://www.nobelprize.org/

[34] OECD - ORGANIZATION FOR ECONOMIC CO-OPERATION AND DEVELOPMENT. Último acceso en 12/04/2013

http://www.oecd.org/

[35] PNUD - PROGRAMA DAS NAÇÕES UNIDAS PARA O DESENVOLVIMENTO. Útimo acceso en 02/06/2013.

http:/www.pnud.org.br/

[36] UNESCO - UNITED NATIONS EDUCATIONAL, SCIENTIFIC AND CULTURAL ORGANIZATION. Último acceso en 02/06/2013.

http:/www.unesco.org/ 


\section{DECLARACIÓN DE COMPROMISO}

Guilherme Hoffmann, el abajo firmante, estudiante del Máster en Marketing Internacional, celebrado en las instalaciones de la UNLP - Universidad Nacional de La Plata, en los años 2011 a 2012, manifiesta que el contenido de la tesis titulada "Negociaciones Interculturales en América Latina: ¿Cómo tratar con diferentes costumbres e identidades nacionales?" es auténtico, original y autoría exclusiva.

La Plata - Argentina, 15 de julio de 2013.

Guilherme Hoffmann 